This is a self-archived version of an original article. This version may differ from the original in pagination and typographic details.

Author(s): Saariluoma, Pertti; Jokinen, Jussi

Title: Appraisal and Mental Contents in Human-Technology Interaction

Year: 2015

Version:

Copyright: @ 2015 , IGI Global

Rights: In Copyright

Rights url: http://rightsstatements.org/page//nC/1.0/?language=en

Please cite the original version:

Saariluoma, P., \& Jokinen, J. (2015). Appraisal and Mental Contents in Human-Technology Interaction. International Journal of Technology and Human Interaction, 11(2), 1-32.

https://doi.org/10.4018/ijthi.2015040101 


\title{
Appraisal and Mental Contents in Human-Technology Interaction
}

\author{
Pertti Saariluoma, University of Jyväskylä, Jyväskylä, Finland \\ Jussi P.P. Jokinen, University of Jyväskylä, Jyväskylä, Finland
}

\begin{abstract}
User experience has become a key concept in investigating human-technology interaction. Therefore it has become essential to consider how user experience can be explicated using psychological concepts. Emotion has been widely considered to be an important dimension of user experience, and one obvious link between modern psychology and the analysis of user experience assumes the analysis of emotion in interaction processes. In this paper, the focus is on the relationship between action types and elicited emotional patterns. In three experiments including $N=40$ participants each, it is demonstrated that the types of emotions experienced when people evaluate and use technical artefacts differ based on the stances they take toward these artefacts. One cannot approach user experience irrespective of the careful analysis of the situation-specific emotional themes. It is essential to any theory of user experience to consider the nature of the situation and relevant actions.
\end{abstract}

Keywords: $\quad$ Action, Cognition, Competence, Emotion, Frustration, Human-Technology Interaction, User Experience, User Psychology

\section{INTRODUCTION}

User experience research has made its way among traditional ways of approaching emotional and aesthetic human-technology interactions, such as Kansei engineering, funology, design for pleasure, affective design, emotional design, and affective ergonomics (Hassenzahl \& Tractinsky, 2006; Kuniavsky, 2003; Law, Roto, Hassenzahl, Vermeeren, \& Kort, 2009; Nagamachi, 2011; Norman, Miller, \& Henderson, 1995; Wright \& McCarthy, 2005). User experience, from a user psychological point of view, can be thought to entail, among other things, a person's emotions and perceptions of interaction (Bargas-Avila \& Hornbaek, 2011; Moran, 1981; Saariluoma, 2003; Saariluoma \& Jokinen, 2014; Saariluoma \& Oulasvirta, 2010). Behind all these research paradigms with very similar goals one can find different ways of applying psychological thinking to understand how people meet technical artefacts, and for this reason it makes sense to ask if the efforts of different approaches in human-technology interaction can be conceptually unified within a common framework (Saariluoma, 2004; Saariluoma \& Oulasvirta, 2010).

In the search for unification, it reasonable to explicate and operationalise modern paradigms within the framework of user psychology 
(Saariluoma, 2005; Saariluoma \& Oulasvirta, 2010). This presupposes using empirical methodologies, experimental paradigms, theoretical concepts, and modern psychological theoretical generalisation. Thus, user psychology could be seen as a similar application area of modern psychology as traffic psychology, school psychology, work psychology, clinical psychology, or geropsychology, which are all divisions within psychology based on an importance of the practical field. This new field of applying psychological thinking would thus entail the whole human dimension of human-technology interaction (Moran, 1981; Saariluoma, 2003). Psychology is, of course, not the only relevant research field in studying user experience. For example, marketing, art research and design, information systems work, and engineering also have important roles in this discourse. However, psychology and cognitive science, as the basic sciences working with the details of human mind, must take part in the discourse on user experience. Thus, it is possible that the other approaches to user experience could eventually be reduced to applied human research and psychology.

The key theoretical notions of modern cognitive scientific and the psychological concept of the mind are anchored to the notions of mental representation, as such derivatives as schemas, productions, or mental models (Anderson, Farrell, \& Sauers, 1984; JohnsonLaird, 1983; Markman, 1999; Neisser, 1976; Newell \& Simon, 1972). The knowledge of mental representations enables psychologists to explain why people behave as they do (Markman, 1999). The very idea of representation is historical and can be found in different forms in the works of philosophers such as Locke and Hume (ideas and impressions), as well as Kant (1781) and Schoepenhauer (1818-1819/1969) (Vorstellung, i.e., representation). However, despite the intuitive clarity of the concept, psychological interpretations of mental representation have varied over the last 40 or 50 years. During this time, representations of emotions have received their own treatment (e.g., Beck,
1976; Dolan, 2002; Maio, 2010; Oatley, 1992; Power \& Dalgleish, 1997).

In modern psychology, the link between emotion and cognition has been justly perceived as important (Schachter \& Singer, 1962). The mental process responsible for combining emotion with cognition is called appraisal (Arnold, 1960; Beck, 1976; Lazarus, 1991; Lazarus \& Lazarus, 1994; Scherer, 2005, 2009). Bower (1981), for example, demonstrated conceptual and empirical connections between cognitions, actions, and the emotional dimensions of memory. Later, representational concepts, such as mental models, semantic networks, and schemas, have become common in discussing emotion and its relation to cognition and action (Ivonin, Chan, Chen, \& Rauterberg. 2013; Oatley, 1992; Ortony, Clore, \& Collins, 1988; Power \& Dalgleish, 1997). Appraisal can be seen as the core process in combining emotional and cognitive mental content. Modern theorists connect appraisal with concurrent action and reaching one's goals (Frijda, 1986; Lazarus, 2001; Scherer, 2005, 2009). Psychologically, personal motivation and action goals are central in the emotion process (Oatley, 1992; Power \& Dalgleish, 1997; Lazarus, 1991), and therefore, in the user psychological framework, it is logical to ask whether the nature of ongoing actions could explain what kind of emotional representations and user experiences people have.

\section{EMOTIONAL USER EXPERIENCE AS A MENTAL PROCESS}

There are several ways of developing theoretical concepts for the mental mechanisms relevant to investigating emotion. First, much research has adopted various system-theoretical models, which assume that emotion processes are carried out by a number of integrated subsystems (Teasdale \& Barnard, 1993). Secondly, one can find representational ideas, such as network-based models for combining cognition with emotion (Bower, 1981). Both models have problems 
in discussing what people feel, whether these feelings are relevant, what the cognitive interpretations of situations are like, and whether cognitive and emotional interpretations make any sense at all. The problem lies in the inherent ambiguity of subsystems and network concepts. A subsystem can produce irrational emotional states, as well as rational ones, and these can entail correct and incorrect information about the reality. Questions pertaining to the relevance and truth of these representations do not make sense unless theories precisely define what the contents of the active information in the mind are. Therefore, we have begun to develop a third line of theoretical thinking within user psychology.

Already, Newell and Simon (1972), Allport (1980), and Fodor (1990) have called the attention of psychologists to the importance of the information contents of mental representations, or mental contents. This notion opens a number of new possibilities for discussing how mental representations can explain human behaviour. Allport (1980) correctly pointed out that many modules of the human nervous system are content-specific. Systems of depth vision, or space and colour, for example, are content-specific and neurally 'hardwired'. Our thinking goes to a slightly different but not contradictory direction, with a leading assumption that each situation, physical or social, activates mental representations in the mind. These mental representations have mental contents, that is, their informational contents. Understanding the information content and its properties within mental representations allows user psychologists to analyse and explain human behaviour during interactions. Therefore, when we examine specific psychological problems, such as aspects of human mental representation, we should analyse the mental contents of relevant representations; operationalise experiments regarding these concepts; and explain human actions, responses, and behaviours on the grounds of the explicated contents of mental representations.

It may be difficult to understand what the notions of mental contents add to the notions of mental representation. The crucial reason is the necessity to investigate differences between different representations. If a group of people hates computer games, they represent their hate in their minds. If another group loves computer games, they represent their love in their minds. Thus, the difference between the first and the second group is not in representing but in the information contents of representations, such as between hate and love. Thus, the groups have different mental contents when they interact with computer games. Consequently, the differences in behaviours between the groups can be explained by means of their emotional contents. People who hate computer games, avoid playing them, and people who love them, do play. The main explanatory ground must be approached from the perspective of the differences in the contents of mental representations, and the respective behaviours must be explained on the ground of mental contents. The approach which studies mental contents and bases the explanation of it, can be called content-based psychology as the explanation of behaviour is based on mental contents (Saariluoma, 2003).

From our point of view, all mental representations have, on one hand, cognitive content elements, including such information as precepts, images, linguistic expressions, concepts, action schemas, and thoughts (e.g., propositions), with specifiable mental contents. On the other hand, active representations have emotional content elements, such as fear and joy, which in the context of appraisal theory of emotion are called feelings to distinguish them from the whole emotion process (Scherer, 2009). This emotional content can be considered in terms of different appraisal dimensions (Smith \& Ellsworth, 1985), such as valence (positive and negative, i.e., pleasant and unpleasant), and in terms of relational theme, that is, what the specific emotion is, such as fear, joy, happiness, or anger (Lazarus, 2001). Thus, for example, fear can be seen as perception or experience of danger in front of a definite target such as death, open spaces, a definite person, or an animal. Conversely, angst can be seen as fear without a definite target (Izard, 2009; Öhman, 2008). 
These two aspects of mental representation are integrated within the process of appraisal (Arnold, 1960; Lazarus, 1991 Moors, Ellsworth, Scherer, \& Frijda, 2013; Power \& Dalgleish, 1997). Thus, the mental contents of an active representation can be seen as a combination of cognitive and emotional contents. The task of psychologists is to uncover the structure of representational contents and use this knowledge to explain and to make understandable the connections between representational content elements and ongoing action.

To take a step forward and to move from abstract principles to concrete empirical settings, it is good to create an empirical investigation that can demonstrate how it is possible to work with combinations of actions, cognitions, and their emotional representations on an empirical level. This presupposes experimental conditions, in which the combination of these three elements, that is, actions, activated cognitions, and their relationships with the activated emotional contents, can be examined. A close reading of user experience literature illustrates that experimental designs often use various types of actions to create measurable experiences (Bargas-Avila \& Hornbaek, 2011; Vermeeren, Law, Obrist, Hoonhout, \& Väänänen-Vainio-Mattila, 2010). The nature of action in experiments can be understood as an experimental presupposition, that is, a tacit assumption built into the way the research problem is operationalised (Saariluoma, 1997). Subjects are, for example, often asked to evaluate and express how they feel when they encounter an interface, but they can also be asked to do tasks with the technical artefacts (e.g., McCarthy, Wright, \& Meekison, 2005; Norman, 2004; Saariluoma \& Jokinen, 2014). We call the first type of situation contemplative to emphasise that the elicited feelings are due to a non-interactive evaluation. The second type is called functional to emphasise that there is interaction. From the present point of view, it is important to ask whether there is a difference in the cognitive and emotional mental contents in the two types of situations, and how the dif- ferences in representation should be understood when analysing user experience.

By keeping the stimuli the same when investigating the properties of the two basic types of actions, it is possible to ensure that the differences in mental contents are caused by the way in which subjects encode the stimuli. One could say that the subjects in functional situations have a different stance than the subjects in contemplative situations. As a consequence of these differing stances, they encode different aspects of the same stimuli, which can be seen in their differing cognitive mental contents. Aspect itself is a concept present in Wittgenstein's (1958) theory of mind. A good example of it is provided by ambiguous figures. Here, we assume that different types of tasks and task-relevant actions activate different mental stances and lead to different cognitive and emotional contents. In this sense, stance differs from other dispositional concepts such as attitude. By stance we refer to the prevailing and active way of directing oneself in a situation, while attitude is a long-term memory scheme, which can activate in any time, but which is like French grammar for someone momentarily speaking English. It is a passive long-term resource, while stance is the active ongoing way of looking things now.

Finally, a reader may ask what the relation between a given stance and mental content is. The answer is that two stances will differ in terms of their content. Thus, to understand what the role of stance in causing differences in behaviour is, we must ask what the cognitive and emotional contents of a particular stance are, as compared to another stance. In clinical psychology, Beck (1976), for example, argued that depressive people encode the world in a more negative manner than normal, that is, they have a more negative stance towards their environments. Our argument is that the stance of the user is one of key factors in user experience.

The concept of stance leads us to a final conceptual nuance. Mental representations control and steer human behaviour (Newell 
\& Simon, 1972). Therefore, the information contents of these representations give people actions and direct them. People often pursuit towards objects and goals which give pleasure and avoid objects and situation which make them feel pain. Thus there is an intimate connection between mental contents and the reasons for why people pursuit towards some specific goals. To content-based psychological thinking, the intimate connection between the direction of action and behaviour and the activated mental contents is a basic assumption. Consequently, prevailing stance, which is a mental content, explain many essential aspect of ongoing action.

The ultimate motivation for our research and explanation for the hypotheses below is to illustrate that emotional states and user experiences depend effectively on the nature of ongoing actions. Different actions elicit different emotional patters and for this reason it is essential to set the questions concerning user experiences in the context of what is done with the given technology, and how it is used. To study how user emotional experience depends on the stance of the user, a set of experiments were designed. The critical experimental manipulation concerned influencing the stance of the user and thus the logic of their emotional user experience responses to the stimuli. The stance of the participants was primarily induced by giving them different tasks for same stimuli, and emotional user experience was measured using a questionnaire. Task performance was also measured. The following hypotheses are presented and investigated in three experiments reported below (see Table 7 in the General discussion section for list of all the hypotheses tested in the experiments reported here):

H1: The stance of the participant affects how different stimuli elicit emotional user experience;

H2: The stance of the participant has an impact on emotional user experience;

H3: Task efficiency has an impact on emotional user experience.

\section{GENERAL METHOD}

\section{Stimuli and Tasks}

Online shopping was chosen as the context of the study because of its familiarity. Currently, most of the people have used or at least heard about online shopping. Furthermore, webpages offer the chance to conduct relatively naturalistic tasks, even in laboratory settings, because the experimental tasks can be conducted using an ordinary computer, just like in real life. Five online shops were chosen as stimuli: Amazon, Apple, Ikea, Boostep, and Jasmine Jewels. The first three were chosen because they were supposedly familiar to most of the participants, and the last two were chosen for their unfamiliarity (each participant also reported his or her familiarity with each of the brands before starting the experiment). The tasks were slightly different in each of the experiments reported below because the questions concerning the nature of emotional user experience varied between the experiments.

The primary experimental manipulation was the stance of the user. This manipulation was performed by asking the user to either just observe the webpages, conduct easy tasks, conduct hard tasks, or conduct impossible tasks. The first stance is called contemplative, and the second is called functional. In terms of the degree of intensity, functional stance varied between the experiments. To induce a contemplative stance, the participants were given a simple task: explore the stimuli passively and look for any stimulating objects. Although this is referred to below as a "contemplative task", no real performance was expected of the participants, and they could not fail or pass the task. To induce a functional stance, the participants were explicitly given tasks and asked to perform them effectively. For each stimulus, there were a number of tasks. In the first experiment, all tasks had to be completed, and in the subsequent experiments, as many of the tasks as possible needed to be completed in the given time. 


\section{Questionnaires}

Experience refers to the conscious part of mental representations, and the contents of experience form this part. The task of the user psychologist is the operationalization of conscious experience in human-technology interaction. Consciousness can be associated with verbalized representational information, that is, people can express their thoughts verbally by having something to say about them (Allport, 1977; Ericsson \& Simon, 1984; e.g., McCarthy, Wright, $\&$ Meekison, 2005). Indeed, in the research on emotion, it has been proposed that self-reports are perhaps the main resource on information about emotional experience (Schorr, 2001). Hence, we assume that questionnaires elicit valid information on the emotional contents of participants. This assumption can be validated by demonstrating how the emotional responses have the expected covariance structures in relation to other measures used in the experiment (Campbell \& Fiske, 1959).

Emotional user experience was measured using questionnaires that were administered after each stimulus. The questionnaire was constructed using a bipolar competence-frustration factor model of emotional user experience (Saariluoma \& Jokinen, 2014). Competence refers to the user's perception that his or her abilities helped in good task performance. Therefore, being efficient, skilful, determined, and vigilant during tasks results in competent feeling (Saariluoma \& Jokinen, 2014). On the other hand, frustration results from goal-incongruent events, that is, when the user faces obstructions for accomplishing tasks (Saariluoma \& Jokinen, 2014). Both factors were operationalized into Likert-scales containing four emotion items. For Competence, these were successful, efficient, determined, and vigilant. The first two let the participants reflect on their own skills and actions related to the notion of self-efficacy (Bandura, 1982). The last two let the participants reflect on their autonomy and attentiveness during their interactions with technology (Carroll \& Thomas, 1988; Hassenzahl, 2008). The items for Frustration were frustrated, anx- ious, confused, and annoyed. As stated above, experiencing frustration and annoyance is the result of not being able to reach one's goals, and anxiety results from unexpected or undefined situations, which can also be confusing (Lazarus \& Lazarus, 1994), making these items suitable for investigating negative emotional responses during interaction with technology.

While the origin of the emotional questionnaire items lies in theories of basic emotion and folk concepts regarding emotion, methodologically, their use does not assume any single theory of emotion. Whether emotions, such as anger, disgust, and fear, are basic (Ekman, 1993; Power $\&$ Dalgleish, 1997) or useful and frequent in communication but not necessarily hardwired (Barrett, 2006; see also Scherer, 2005), the important aspect of the questionnaire is that the participants can reliably report their personal emotional experience with familiar emotion words (Saariluoma \& Jokinen, 2014). The validity of the scales will, of course, be investigated throughout the experiments via repeated reliability tests and via observing the expected correlations with other self-ratings and objective experimental measurements (Campbell \& Fiske, 1959; Nunnally \& Bernstein, 1994).

In addition to the aspects of emotional user experience, the questionnaire also contained scales regarding the feeling of control and a semantic differential scale for appraising the hedonic qualities of the stimuli. However, only the two emotional user experience factors used in the analyses are reported here. In addition to the questionnaires filled out during the experiment, the participants filled out a questionnaire concerning their brand experience with the brands used in the experiment. This questionnaire was filled out before the tasks, and its purpose was to control for brand satisfaction (for discussion of brand experience and user experience, see Law, Roto, Hassenzahl, Vermeeren, $\&$ Kort, 2009). For example, if a participant was very satisfied with the products and user experience of a given brand, it was likely that this would influence the user experience during the experimental tasks. The brand questionnaire contained two factors, brand satisfaction and 
brand trust. Brand Satisfaction was used as a control variable in the models reported here, but brand trust will not be utilized in analyses in this article, because it was reserved for different investigations. In addition to the brand questionnaire, the participants used a four-item scale to assess their amounts of self-confidence at the start of the experiment. The items were certain, determined, ready, and vigilant, but based on the reliability analysis, vigilance was retained from the summated scale, and only the remaining three items were used to construct the Self-confidence scale. Self-confidence was measured for control purposes as a 'baseline variable' because it is known that some amount of variance in emotional experience can be explained by the overall mood of the respondent (Schorr, 2001). Specifically, the studies of self-efficacy demonstrate how the individual's perception of her own operational abilities have an effect on how well the individual performs (e.g., Bandura, 1982). All questionnaire items are included in Tables 8-9 (see Appendix A).

\section{Analysis}

The reliability of the scales was investigated with multidimensional scaling (MDS), Cronbach's alpha, and factor analysis. MDS is a statistical method that is useful for producing two-dimensional representations of the correlations between items (Kruskal \& Wish, 1978), and it was used to confirm the bipolarity of the competence-frustration model of emotional user experience (Saariluoma \& Jokinen, 2014). Two-dimensional configurations, displaying the Euclidian distances between the Z-score standardized emotional questionnaire items are displayed in the results sections. This is similar to the method used by Russell (1980) in his studies of circumplex model of affect, later generalized as the theory of core affect (Russell, 2003). However, while core affect theory provides a useful model for the analysis of valence and arousal in emotional user experience, we feel that appraisal theory offers better understanding on the relationship between the stance of the user and her emotional process.
Cronbach's alpha was used to assess the reliability of all scales of the study. The summated scales were constructed by using a regression method on the factor scores obtained with a maximum likelihood factor analysis. This resulted in standardized sum variables, the mean of which was 0 and the variance of which was the factor score covariance of the items. The data for the factor analysis were pooled so that the analysis for all five stimuli would be conducted at the same time. Hence, although the grand mean of Competence and Frustration for any experiment was 0 , differences between the groups and within stimuli were possible. However, the reliabilities were also tested between experimental groups.

Hypotheses were tested using multilevel modelling, which allows for complex withinsubject data structures (Hox, 2010). In models reported here, the five stimuli are nested within the participants and treated as random variables, except when testing for $\mathrm{H} 1$, which requires stimuli to be a fixed effect. Each hypothesis was tested separately for Competence and Frustration. H1 was investigated with a simple interaction model, testing the interaction effect of the stimuli and the stance of the participant on the mean emotional user experience. H2-4 were tested with a more complex model. The continuous fixed effects in the models were Brand Satisfaction and Self-confidence. The categorical fixed effect was the stance of the participants. In the results sections, we report the coefficients (with errors) and the standardized coefficients or the fixed effects (Hox, 2010). The effect sizes for the models in the three experiments reported here are included in Appendix B. Finally, at the end of the analysis of each experiment, an item-level analysis of the emotional items was conducted.

\section{EXPERIMENT 1}

\section{Method}

$N=40$ participants, 19 men and 21 women, were recruited for the experiment. Their mean 
age was $27.9(S D=7.7)$, and their age range was $18-57$. The participants were recruited from an introductory university course on human-technology interaction. Participating in an experiment was not compulsory for the students, but they had to choose between a written assignment and participation in a laboratory experiment. All participants were familiar with the online shopping context: all had heard about some of the brands and visited at least some of the web pages used in the experiment. Nine participants had never bought anything from any of the listed online shops, but the others had.

The experimental design was a betweensubjects design with within-subjects tasks. Half of the participants were assigned to the contemplative group, and the other half were assigned to the functional group. The groups were balanced in terms of gender and age and did not differ significantly in their online shopping experience (non-significant $\chi^{2}$ and $t$-tests for all relevant background variables between the groups). Participants in both groups were presented with five stimuli (the five online shops) in a counterbalanced order.

The task of the contemplative group was to examine a series of screenshots of an online shopping webpage, and the task of the functional group was to conduct two tasks: look for a certain product and add it to the shopping chart, and find the feedback form. The contemplative group were shown three screenshots for each webpage, 30 seconds each ( 90 seconds total). The screenshots were taken from the locations of the pages at which the functional group would conduct the tasks. The functional group was given as much time as needed to complete the tasks, and they took 199 seconds on average ( $m d n=182$ s., $S D=138$ s.). In the analysis, completion time is taken to indicate task efficiency: more efficient task completion results in faster completion time, as this was the only criteria of performance.

\section{Results}

The two-dimensional configuration of the emotional user experience questionnaire items between the contemplative and functional groups is shown in Figure 1, which shows a clear bipolar configuration (factor loadings are listed in Appendix B). The reliability of Competence was $\alpha=.87$ for the contemplative group and $\alpha$ $=.92$ for the functional group. The reliability of Frustration was $\alpha=.77$ for the contemplative group and $\alpha=.89$ for the functional group. Both the bipolar structure and high reliabilities provided support to the measurement model used for emotional user experience.

Figure 2 depicts the mean Competence by webpage and by group and illustrates how, in the contemplative group, no difference between the webpages was observed, whereas in the functional group, the stimuli are clearly differentiated according to their mean Competence. A similar differentiation can be observed in the means for Frustration. The difference in the means for Competence was statistically significant in the functional group, $F(4,190)$ $=12.8, p<.001$, but not in the contemplative group, $F(4,190)=0.6, p=0.687$. The interaction effect between the group and the stimulus was statistically significant, $F(9,190)=6.0$, $p<.001$. Likewise, Frustration had differing means between the stimuli in the functional group, $F(4,190)=12.9, p<.001$, but not in the contemplative group $F(4,190)=0.9, p=$ 0.478 . The interaction effect between group and stimulus was statistically significant, $F(9$. $190)=6.1, p<.001$. These results support H1 and illustrate that only the participants with the functional stance had variance in terms of emotional experience based on the stimulus.

Although a clear effect of stance on emotional response was observed, there were relatively small group differences in terms of the grand means of emotional user experience. This is shown in the multilevel model (Model 1, Table 1), in which no between-subjects group effects, that is, support for $\mathrm{H} 2$, are found. This result will be discussed below; a post-hoc analysis shows how this result can be explained by differing sources of variation in emotional user experience between the two experimental groups. The second multilevel 
Figure 1. Configuration of emotional questionnaire items between the groups
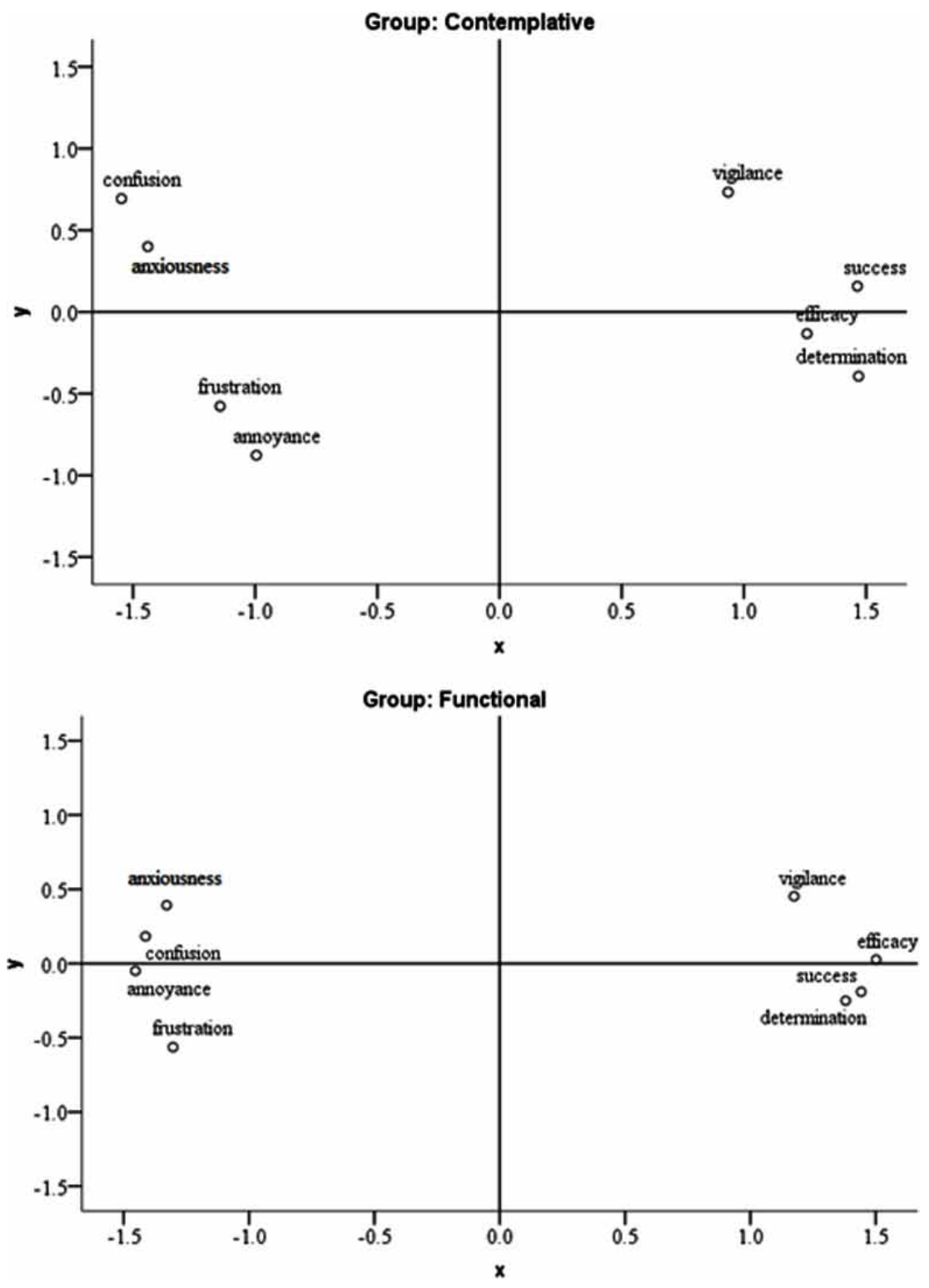

models for Competence and Frustration (Model 2 , Table 1) including only participants from the functional group indicate that the variance in emotional user experience in this group can be explained by task efficiency (H3). Increased task times predict decreased Competence and increased Frustration. In other words, failure to perform tasks efficiently causes frustration, while efficient task completion has a positive impact on competence.

To assess the possibility that the emotional responses of the contemplative group actually reflected their overall self-confidence and not the emotions elicited by the stimuli, we performed a post-hoc analysis and correlated Self-confidence before the test with 
Figure 2. Mean competence between the web shops in functional and contemplative groups

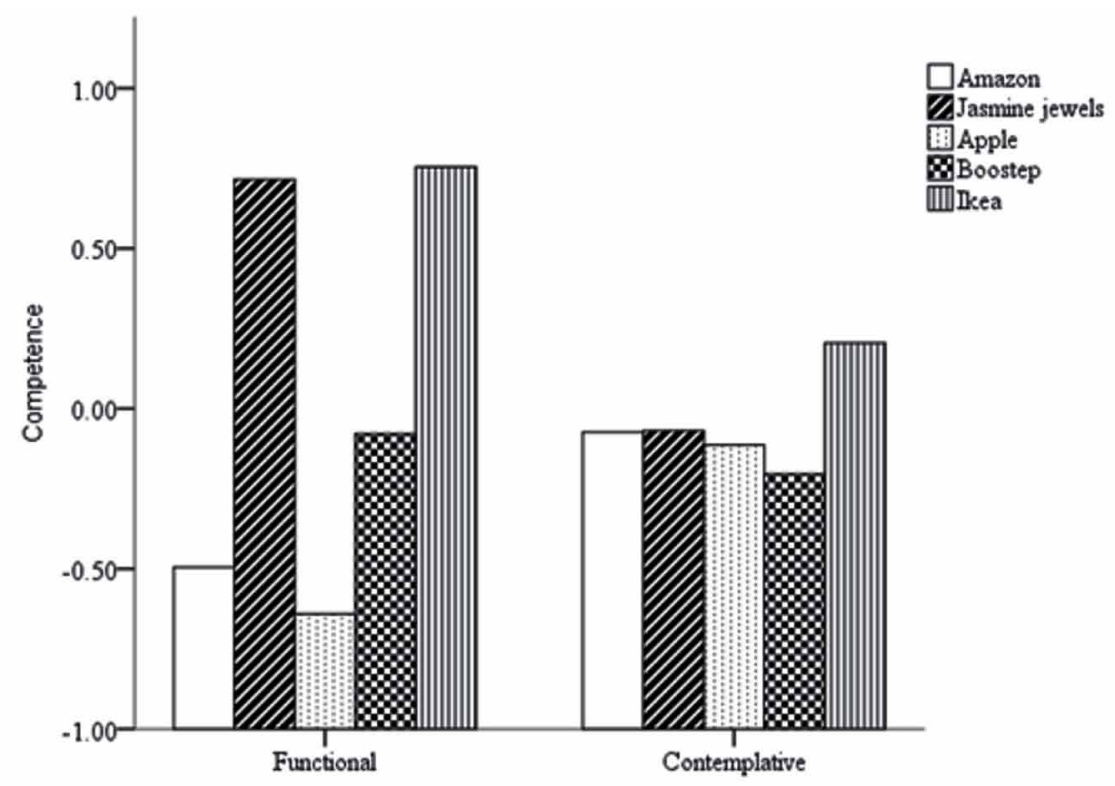

Table 1. Fixed coefficients and random level variances in multilevel models of competence and frustration

\begin{tabular}{|c|c|c|c|c|}
\hline & \multicolumn{2}{|c|}{ Competence } & \multicolumn{2}{|c|}{ Frustration } \\
\hline & Coefficient (s.e.) & Std. Coef. & Coefficient (s.e.) & Std. Coef. \\
\hline & \multicolumn{4}{|c|}{ Model 1} \\
\hline Intercept & $3.26 * *(0.07)$ & & $1.56 * *(0.06)$ & \\
\hline Brand satisfaction & $0.04(0.06)$ & & $0.06(0.05)$ & \\
\hline Self-confidence & $0.29 * *(0.06)$ & 0.29 & $-0.20 * *(0.04)$ & 0.21 \\
\hline \multirow[t]{2}{*}{ Group } & $-0.02(0.11)$ & & $0.04(0.08)$ & \\
\hline & \multicolumn{4}{|c|}{ Model 2} \\
\hline Intercept & $11.21 * *(0.95)$ & & $-2.48 * *(0.78)$ & \\
\hline Brand satisfaction & $0.14(0.08)$ & & $-0.13(0.06)$ & \\
\hline Self-confidence & $0.11(0.08)$ & & $0.08(0.07)$ & \\
\hline Time & $-0.66^{* *}(0.08)$ & -0.58 & $0.34 * *(0.07)$ & 0.31 \\
\hline
\end{tabular}

Note: Model 1: $N=40$. Cases included $=200$. Model 2: $N=19$. Cases included $=95 . * * p<.01, * p<.05$. The reference for group effect is contemplative. 
Competence and Frustration separately for the contemplative and functional groups (the mean of self-confidence between the groups was not different). The result was as expected. In the functional group, Self-confidence correlated only weakly with Competence $(r=.15)$ and moderately with Frustration $(r=-.28)$, but in the contemplative group, the correlations were stronger: Competence $r=.56$ and Frustration $r$ $=-.36$. Although the differences in the correlation coefficients are not statistically significant, the trend is clear and expected. Because the emotional user experience responses in the contemplative group did not reflect the stimuli (H1, see above), this analysis seems to conclude that the Self-confidence before the experiments affects the emotional user experience responses more for the participants with the contemplative stance. This was especially true for Competence, but it was also true for Frustration.

Next, post-hoc item-level analyses were conducted to explore the details of emotional user experience. This is also one way to analyse the mental contents, especially their changes, in detail; this knowledge supports the interpretation of the relevant mental contents. Table 2 presents the means of the eight emotional user experience items. It also presents the Spearman correlation between Self-confidence and the items, and the Mann-Whitney $U$-tests for the difference in the distributions of the items between the contemplative and functional groups. Spearman correlation was used, because the individual questionnaire items cannot be considered as continuous variables. The $\alpha$-level for the Mann-Whitney $U$-tests was calculated using a Bonferroni correction by dividing 0.05 by the number of tests for each factor (four), resulting in $\alpha=0.0125$. The results of posthoc analysis illustrate that while the majority of the distributions of the emotional items did not differ between groups, the effect of Selfconfidence (Spearman correlations) was larger in the contemplative group.

\section{Discussion}

The first experiment resulted in two major notions. First, emotional user experience can be observed in terms of two different clusters, which in terms of content, can be interpret as competence and frustration. The same bipolar clustering of emotions, as defined by variation between the emotional questionnaire items,

Table 2. Spearman correlation coefficients between self-confidence at the start of the experiment and the items of the emotional user experience factors. Means and the standardised MannWhitney U-test for the difference in the distributions between the functional and contemplative groups are also displayed.

\begin{tabular}{|c|c|c|c|c|c|}
\hline \multirow{2}{*}{ Item } & \multicolumn{2}{|c|}{ Functional } & \multicolumn{2}{|c|}{ Contemplative } & \multirow{2}{*}{ MWU } \\
\hline & $\rho$ & $\mathbf{M}$ & $\rho$ & M & \\
\hline success & .22 & 3.5 & .64 & 3.4 & -0.7 \\
\hline determination & .15 & 3.4 & .59 & 3.3 & -0.7 \\
\hline efficacy & .11 & 3.1 & .44 & 3.0 & -0.7 \\
\hline vigilance & .07 & 3.3 & .41 & 3.4 & 0.3 \\
\hline frustration & -.44 & 1.6 & -.30 & 1.3 & -1.9 \\
\hline anxiousness & -.48 & 1.6 & -.49 & 1.9 & 1.5 \\
\hline confusion & -.29 & 2.0 & -.55 & 2.0 & 0.8 \\
\hline annoyance & -.41 & 1.6 & -.50 & 1.2 & $-3.6^{*}$ \\
\hline
\end{tabular}

Note: $N=40$ (20 each group). $\rho=$ Spearman correlation coefficient. MWU $=$ Standardised Mann-Whitney $U$-test statistic. ${ }^{*} p<.0125$. 
had been observed earlier (Saariluoma \& Jokinen, 2014). The second notion concerns the hypotheses, two of which were supported and one of which was not. H1 was supported by confirming the interaction effect between the stimulus and the stance of the participant. Only in the functional group were there observable differences between the stimuli in terms of emotional user experience. However, contrary to $\mathrm{H} 2$, there were no observable differences in the mean Competence or Frustration between the functional and contemplative groups.

There is a confounding factor in the results, because the contemplative tasks were shorter than the functional tasks. However, there are no previous models or evidence to suggest that the contemplative evaluation of a task would differ significantly depending on whether the contemplation lasts 90 or 200 seconds. Instead, we propose that the observed differences between the groups in the logic of emotional user experience process is indeed due to the different stances of the users. This differs notably from the discussion of the time-span of user experience, in which the distinction between experience before and experience after use is made (Roto, Law, Vermeeren, \& Hoonhout, 2011). Instead, the argument here is that the logic of momentary user experience, that is the experience during the actual use, is different depending on the stance of the user. Further, as the post-hoc analysis demonstrates, the logic of how experience before the use affects the experience during or straight after the use is different depending on the stance of the user.

The results above can therefore be understood in more detail with the help of the post-hoc analysis, which suggests that in the contemplative group, the role of the pre-test self-confidence of the participants had a larger impact on the self-reports of emotional experience. It is probable that while the participants concerned with the functional tasks were able to have emotional user experience as a response to what happened during the interaction, the participants concerned with the contemplative tasks were not emotionally affected by the stimuli and thus returned to their baseline self-confidence. This line of thought receives further support from the investigation of $\mathrm{H} 3$. An increase in task time can be interpreted to indicate difficulty in completing the tasks, which is visible in increased frustration and decreased competence. This finding makes an interesting addition to discussion to self-efficacy (e.g., Bandura, 1982). It is known that the belief in one's own operational abilities affects emotional experience, but here it is demonstrated that this connection is dependent on the stance of the individual during the task.

Contemplative tasks are not therefore sufficient stimuli for studying emotional user experience in its totality. Comparing the standardized coefficients, it seems that competence is especially dependent on task efficiency, supporting the interpretation that competence is related to experienced self-efficacy and control (Bandura, 1982). However, competence is not the same as self-efficacy or control. While self-efficacy is the individual's perception of her own operational abilities (Bandura, 1982), competence as emotional user experience factor is reflects how the user was actually able to bring out efficient task performance. On the other hand, the ability to cope with the task and exert control over the task events is necessary for feeling competent, but feeling of control is thematically different from feeling of competence. The negative relationship between task efficiency and frustration is also understandable: obstructions and other difficulties in tasks are visible in the form of frustration (Lazarus \& Lazarus, 1994). Frustration is the result of obstructive task events which are perceived to be goal-incongruent, but which cannotbe solved efficiently in order to maintain goal-congruence.

The discussion above illustrates how appraisal theory of emotion provides understandable explanation to why the studies of emotional user experience need to take into account the stance of the user. While the circumplex model of affect (Russell, 1980) is useful in grouping the emotional items and thus confirming the bi-polarity of the competence-frustration model of emotional user experience, its ability to explain differences between contemplative 
and functional stance is lower than that of the appraisal theory. Of course, one could argue that the arousal dimension could explain differences between the groups, but this dimension has been observed to be less definitive than valence (Saariluoma \& Jokinen, 2014), and it is not clear how differences in arousal alone could explain the results.

\section{EXPERIMENT 2}

The first experiment suggested that emotional user experience in functional tasks might depend on the difficulty of the tasks. This was visible in the differing explanations for Competence and Frustration between the functional and contemplative groups. What was it about the functional tasks, besides task time, that caused emotional responses? Was frustration, for example, caused by difficulties during the task, or can competence be explained by successful conduct? To investigate this, the second experiment concentrated on the difficulty of the functional tasks. Participants conducted either easy or difficult tasks. Easy tasks were designed to be accomplishable quickly: the relevant hyperlinks were easy to locate and the average amount of steps one needed to complete was small. Difficult tasks, on the other hand, had obscure links which the user had to find, and the number of steps in the task process was large.

Emotional user experience can be shown to be the result of the type of the stance (H1 and $\mathrm{H} 2$ ). It is interesting to contrast this with $\mathrm{H} 3$, which posits that the number of successfully conducted tasks affects emotional user experience. Therefore, the question is whether it is the nature of the stance or the actual events during the tasks that elicit emotional responses. In order to investigate this question, we hypothesize that the effect of task efficiency on user experience is mediated by task difficulty, which can be stated as follows:

H4: The stance of the participant affects the impact of task efficiency on emotional user experience.

\section{Method}

$N=40$ participants, 20 men and 20 women, were recruited for the experiment. Their mean age was $27.2(S D=9.5)$, and their age range was 19-56. None of the participants from the first experiment participated in the second experiment. The participants were recruited from the same course as in the first experiment, and all had at least some experience with visiting online shops or buying products from them. The experimental design was a between-subjects design. Half of the participants were assigned to an easy-tasks group, and the other half were assigned to a difficult-tasks group. The groups were balanced in terms of gender and age and did not differ in online shopping experience (non-significant $\chi^{2}$ and $t$-tests for all relevant background variables between the groups). Participants in both groups were presented with five stimuli in a counterbalanced order. Each participant was given 300 seconds for each stimulus, and they were instructed to perform as many tasks as possible. A successful task completion was indicated by the experimenter, who then provided the next task. The number of tasks accomplished was recorded (the ongoing task upon reaching the time limit was not counted).

\section{Results}

The two-dimensional configuration of the emotional user experience items between the easy-tasks and the hard-tasks groups are shown in Figure 3, which shows a clear bipolar configuration. The factor loadings of the emotional factors are presented in Appendix B. The reliability of Competence was $\alpha=.83$ for the easy-tasks group and $\alpha=.86$ for the hard-tasks group. The reliability of Frustration was $\alpha=.72$ for the easy-tasks group and $\alpha=.88$ for the hard-tasks group. As in the first experiment, a clear bipolar configuration and adequate reliabilities were observed.

In the first experiment, a difference in emotional user experience responses between the stimuli was observed in the functional group, 
Figure 3. Configuration of the emotional questionnaire items between the groups
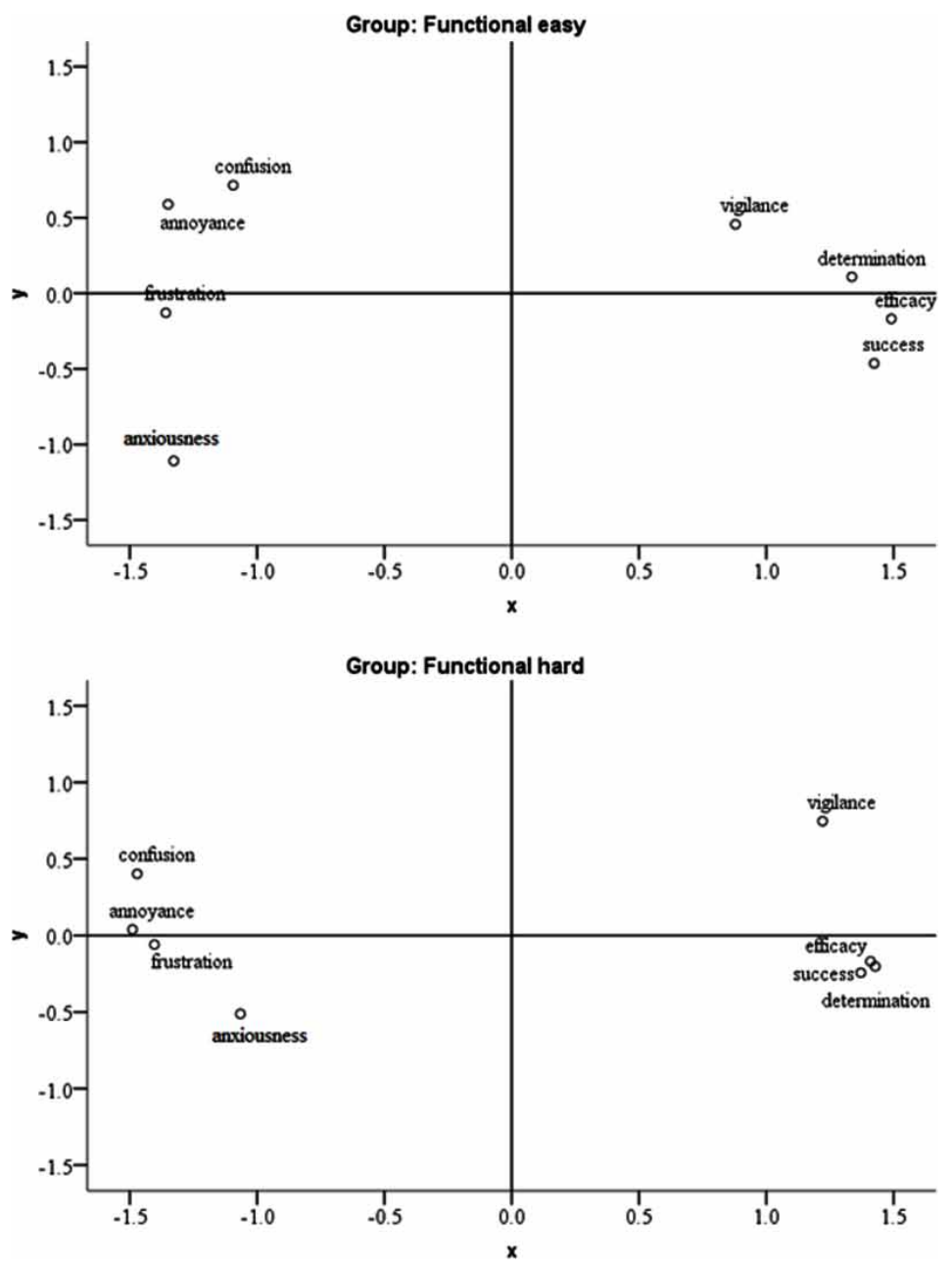

but not in the contemplative group. In the second experiment, a similar effect was observed between the easy-and hard-tasks groups. The mean of Competence differed between the stimuli in the hard-tasks group, $F(4,190)=5.4, p<.001$, but not in easy tasks group, $F(4,190)=2.2, p=$ .069. The interaction effect between the group and the stimulus was statistically significant, $\mathrm{F}(9,190)=4.0, p<.001$. Likewise, Frustration had differing means between the stimuli in the hard-tasks group, $F(4,190)=4.3, p<.001$, but not in the easy-tasks group, $F(4,190)=1.3, p$ $=0.282$. The interaction effect between group and stimulus was statistically significant, $F(9$.
$190)=5.1, p<.001$. As in the first experiment, these results support $\mathrm{H} 1$ and illustrate how the stance of the participant influences his or her emotional user experience responses.

The means of Competence and Frustration by task difficulty group are shown in Figure 4. As hypothesized (H2), the mean emotional user experience differs between the stances. The multilevel models, as shown in Table 3, support this result by showing a statistically significant group effect for both Competence and Frustration. The models also provide support for $\mathrm{H} 3$, suggesting that the number of tasks completed affects both Competence and 
Figure 4. Means of competence and frustration by group
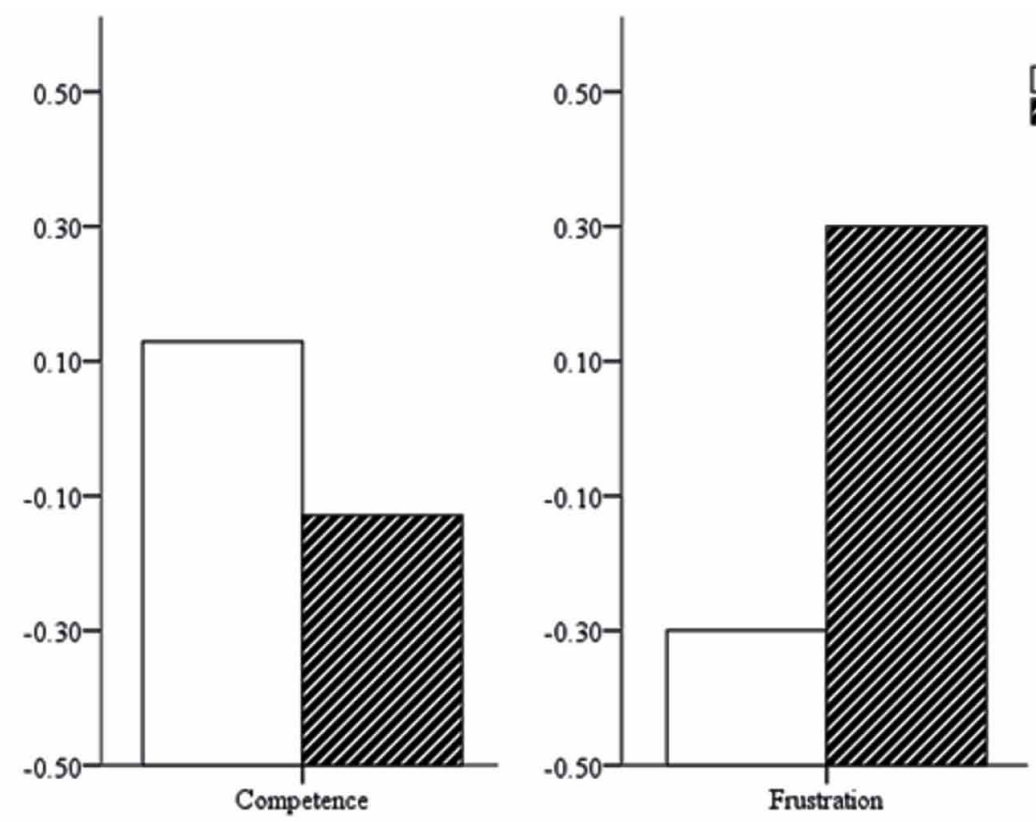

Table 3. Fixed coefficients and random level variances in multilevel models of competence and frustration

\begin{tabular}{|l|l|l|l|l|}
\hline \multirow{2}{*}{\multicolumn{1}{|c|}{ Intercept }} & \multicolumn{2}{c|}{ Competence } & \multicolumn{2}{c|}{ Frustration } \\
\cline { 2 - 5 } & \multicolumn{1}{|c|}{ Coefficient (s.e.) } & Std. Coef. & \multicolumn{1}{c|}{ Coefficient (s.e.) } & Std. Coef. \\
\hline & $-0.92 * *(0.19)$ & & $0.29(0.19)$ & \\
\hline Brand satisfaction & $0.14 *(0.06)$ & 0.16 & $-0.06(0.06)$ & \\
\hline Self-confidence & $0.05(0.07)$ & & $0.02(0.06)$ & \\
\hline Group & $-0.54 *(0.27)$ & & $1.07 * *(0.27)$ & \\
\hline Tasks & $0.22^{* *}(0.03)$ & 0.52 & $-0.13 * *(0.03)$ & -0.29 \\
\hline Group $\times$ tasks & $0.18^{* *}(0.06)$ & & $-0.20 * *(0.06)$ & \\
\hline
\end{tabular}

Note: $N=40$. Cases included $=200 .{ }^{* *} p<.01,{ }^{*} p<.05$. The reference for group effect is contemplative.

Frustration. Further, the statistically significant interaction effect (Group $\times$ tasks) in the models supports $\mathrm{H} 4$, that is, the magnitude of the effect of task efficiency on emotional user experience is dependent on the task difficulty. Figures 5 and 6 illustrate the effect of the number of tasks completed on Competence and Frustration by task difficulty. Low competence is observed in both groups if the participant is unable to complete tasks, but as the number of completed tasks increases, Competence increases also. This effect is larger for the group conducting difficult tasks: being able to accomplish difficult tasks provides for a greater feeling of competence than being able to accomplish the same number of easy tasks. The same is true, but inversely, for 
Figure 5. Regression lines for competence by tasks completed and by task difficulty

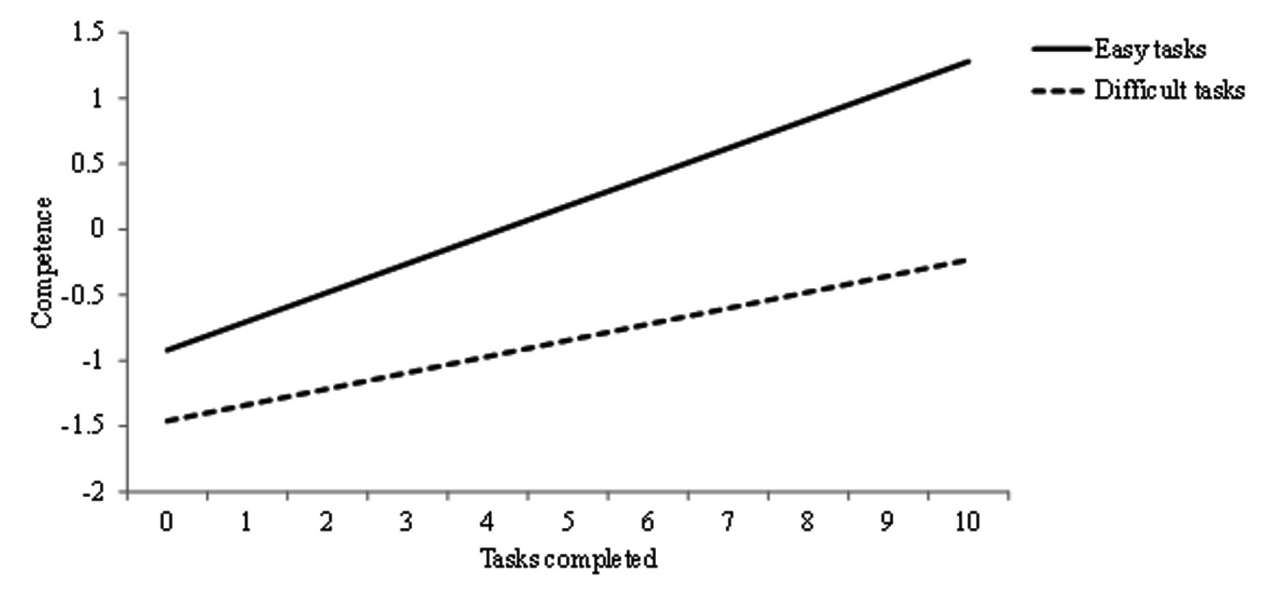

Figure 6. Regression lines for frustration by tasks completed and by task difficult

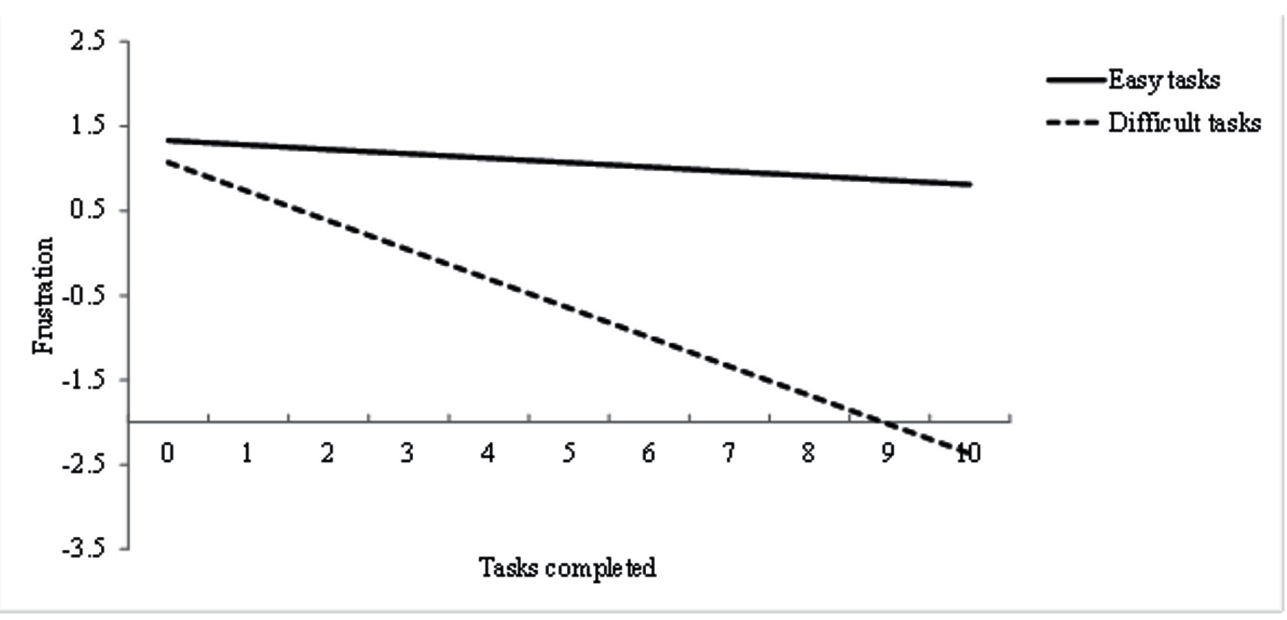

frustration. Being able to conduct many tasks will result in the same relatively low level of frustration for both groups, but failing at difficult tasks causes more frustration than failing at easy tasks.

The item-level analysis, shown in Table 4, supports the findings of the multilevel model, especially for Frustration. However, not all of the results are statistically significant, reflecting the fact that item-level analysis and averaging across tasks decreases the statistical power of the analyses. The directions of the effects are, however, as hypothesized. Also, it is evident that baseline Self-confidence more greatly determines emotional user experience when conducting easy tasks than when conducting hard tasks. As in the previous experiment, the mean of self-confidence did not differ between the groups.

\section{Discussion}

The second experiment investigates the suggestion from the first experiment, emotional user 
Table 4. Spearman correlation coefficients between self-confidence at the start of the experiment and the items of emotional user experience factors. Means and the standardised Mann-Whitney $U$-test for the difference in the distributions between easy and hard-task groups are also displayed.

\begin{tabular}{|c|c|c|c|c|c|}
\hline \multirow{2}{*}{ Item } & \multicolumn{2}{|c|}{ Functional Easy } & \multicolumn{2}{|c|}{ Functional Hard } & \multirow[t]{2}{*}{ MWU } \\
\hline & $\rho$ & $\mathbf{M}$ & $\rho$ & $\mathbf{M}$ & \\
\hline success & -.02 & 3.2 & .33 & 3.0 & -1.7 \\
\hline determination & .22 & 3.2 & .25 & 3.0 & -1.6 \\
\hline efficacy & .13 & 2.9 & .12 & 2.6 & -1.8 \\
\hline vigilance & -.04 & 3.2 & .14 & 3.1 & -0.42 \\
\hline frustration & -.30 & 1.7 & .16 & 2.3 & $2.7^{*}$ \\
\hline anxiousness & -.33 & 1.6 & .05 & 2.1 & 2.4 \\
\hline confusion & -.04 & 2.3 & .09 & 2.8 & $2.7^{*}$ \\
\hline annoyance & -.25 & 1.7 & -.01 & 2.2 & 2.4 \\
\hline
\end{tabular}

Note: $N=40$ (20 each group). $\rho=$ Spearman correlation coefficient. MWU $=$ Mann-Whitney $U$-test score. ${ }^{*} p<.0125$.

experience in functional situations depends on task difficulty, in more detail. The results start to build an understandable picture of emotional user experience as a function of what happens during the interaction. The interaction effect of the stance of the participant and the effect of stimulus on emotional user experience responses was supported (H1). Furthermore, the multilevel models display statistically significant main effects for task difficulty (H2) and tasks completed (H3), as well as for the interaction between these two (H4). This means that failing at tasks causes frustration and succeeding at tasks supports competence and that merely by having to perform difficult tasks, the user becomes frustrated. However, if the user does succeed in difficult tasks, frustration decreases more quickly. Being able to overcome challenging and frustrating situations has a greater effect on emotional user experience than being able to conduct easy tasks. The support provided for all hypotheses increases the plausibility of the assertion that the stance of the user is a major contributor to emotional user experience.

The item-level analyses reflect the results of the first experiment. While, in the first experiment, it was found that baseline Self-confidence predicts emotional responses more greatly in the contemplative group than in the functional group, this same effect can be observed as a function of the intensity of the tasks. Baseline Selfconfidence was more predictive of emotional responses in the group performing easy tasks than in the group performing difficult tasks. In other words, when investigating emotional user experience, when assessing the validity of the measurements, a careful analysis of the stance of the user based on the analysis of individual differences and task nature is necessary.

\section{EXPERIMENT 3}

The second experiment explored our main thesis about the functionality of emotional user experience in more detail. Based on the two experiments, we maintain that the stance of the user is a determinant of emotional user experience. Furthermore, it is maintained that stance affects how the other determinants of emotional user experience cause emotional states. In the final experiment, the contemplative stance, the functional stance, and varying levels of difficulty are brought together and investigated in a within-subjects experiment in which all subjects adopt contemplative and functional stances. 


\section{Method}

$N=40$ participants, 20 men and 20 women, were recruited for the experiment. Their mean age was $23.3(\mathrm{SD}=5.9)$, and their age range was 18-44. The participants in this experiment did not participate in the first two experiments described above. The participants were recruited from the same introductory course as those for the first two experiments, and all had at least some experience visiting or shopping at online shops. The first and second experiment had a between-subjects design in which the participants were grouped either into functional or contemplative groups or easy- and hard-tasks groups. In the third experiment, these two experimental manipulations were brought together. A within-subjects design was used, with all participants conducting contemplative, easy functional, and hard functional tasks.

The experiment was conducted in two task blocks. In the first task block, each participant conducted contemplative tasks by looking at screen shots of webpages for 90 seconds, and then filling out the user experience questionnaire. After five webpages had been evaluated in this way, in the second task block, the participants conducted functional tasks with the five webpages and used questionnaires to assess their user experience. For three of the five stimuli, the participants were asked to complete as many easy everyday tasks as they could in 300 seconds. For the other two stimuli, the participants were also given 300 seconds to complete as many tasks as possible, but the given task was impossible to complete. Impossible tasks were designed so that they sounded genuine tasks, but it was actually impossible to perform them (e.g., asking to check the price of a non-existing product). The assignment of impossible tasks for various stimuli was counter-balanced so that each webpage had participants performing easy and impossible tasks. This resulted in three task levels: contemplative (in the first task block), easy (in the second task block), and impossible (in the second task block). The order of the pages was counterbalanced in both the contemplative and functional task blocks.

\section{Results}

The two-dimensional configuration of the emotional user-experience items between the contemplative-tasks, easy-tasks, and impossible-tasks groups is shown in Figure 7, which displays a clear bipolar configuration. The factor loadings of the items regarding emotional user experience factors are presented in Appendix B. The reliability of Competence was $\alpha=.85$ for the contemplative group, $\alpha=.88$ for the easytasks group, and $\alpha=.84$ for the impossible-tasks group. For Frustration, the reliabilities were $\alpha=$ .76 for the contemplative group, $\alpha=.85$ for the easy-tasks group, and $\alpha=.81$ for the impossibletasks group. The results replicate the results of the dimensional and reliability analyses from the first two experiments.

An interaction effect between the stance of the participant and the stimulus was observed, as in the first and the second experiments. The interaction effect for Competence was $F(14,385)=11.6, p<.001$, and the interaction effect for Frustration was $F(14,385)=$ $18.9, p<.001$, providing yet more support for $\mathrm{H} 1$, which states that stance has an impact on how emotional responses are elicited. The difference between the means of Competence and Frustration between the three stances (H2) is shown in Figure 8. Competence for impossible tasks is significantly lower than for easy or contemplative tasks, but there is no statistically significant difference between contemplative and easy tasks, as shown in the multilevel model in Table 5. With Frustration, the effect is clearer: Frustration was observed to be higher in both the easy and impossible task levels than in contemplative task level and higher in impossible tasks than in easy tasks. Task efficiency affected user experience as hypothesized (H3) by increasing Competence and decreasing Frustration. The effect was, of course, observed only in the easy-tasks group. In the contemplative-stance group there were no tasks to accomplish, and number of impossible tasks accomplished was always zero.

Item-level analyses are shown in Table 6 and restate the findings from previous ex- 
Figure 7. Configuration of the emotional questionnaire items between the task levels
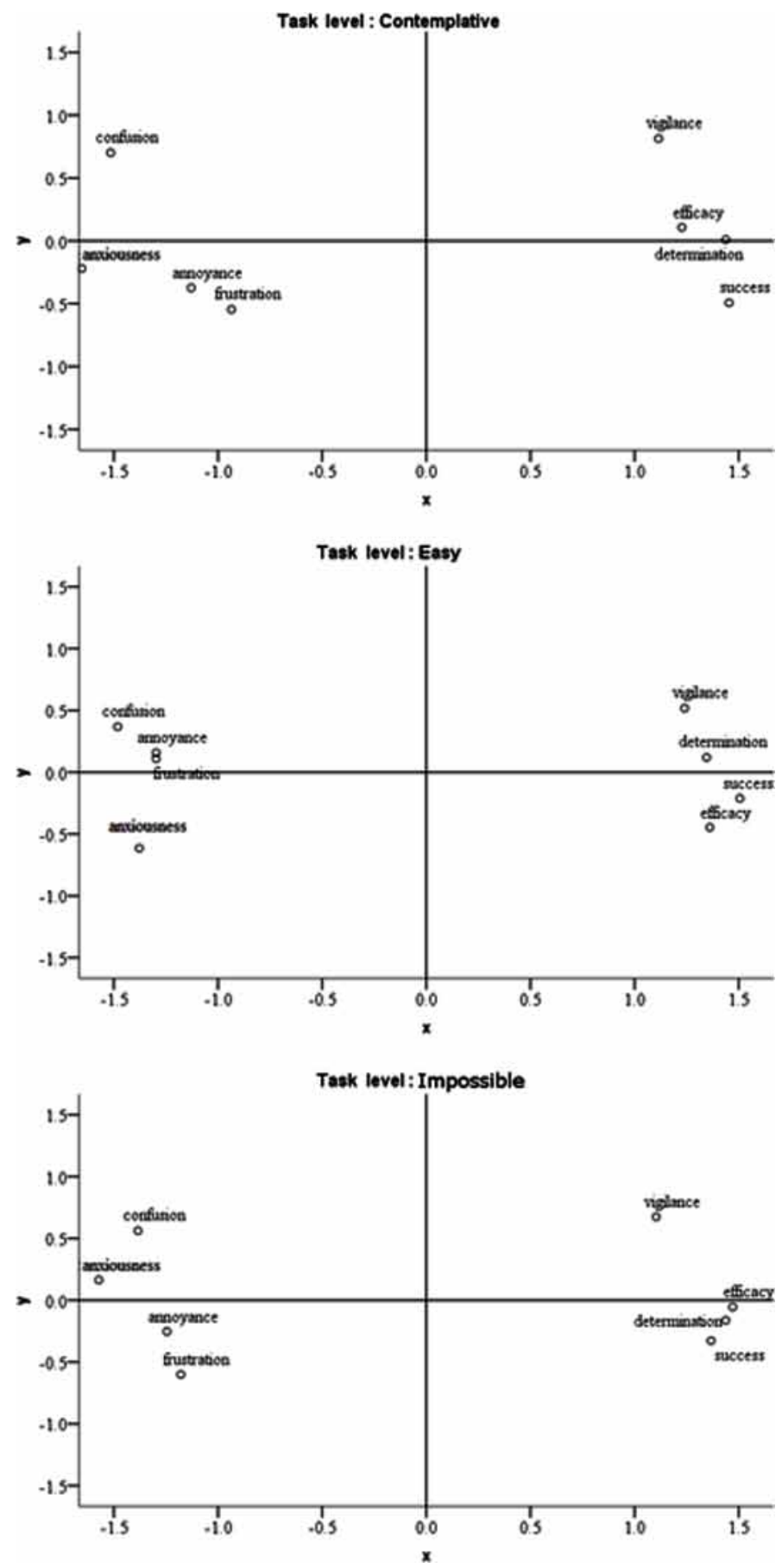

Copyright $(\mathbb{C} 2015$, IGI Global. Copying or distributing in print or electronic forms without written permission of IGI Global is prohibited. 
Figure 8. Means of competence and frustration by task level


Table 5. Fixed coefficients and random level variances in multilevel models of competence and frustration

\begin{tabular}{|c|c|c|c|c|}
\hline & \multicolumn{2}{|c|}{ Competence } & \multicolumn{2}{|c|}{ Frustration } \\
\hline & Coefficient (s.e.) & Std. Coef. & Coefficient (s.e.) & Std. Coef. \\
\hline & \multicolumn{4}{|c|}{ Model 1} \\
\hline Intercept & $0.22 * *(0.05)$ & & $-0.48 * *(0.03)$ & \\
\hline Brand satisfaction & $0.14 * *(0.04)$ & & $-0.07 *(0.03)$ & 0.07 \\
\hline Self-confidence & $0.28 * *(0.04)$ & & $-0.04(0.03)$ & \\
\hline Tasks $=$ impossible & $-1.08 * *(0.10)$ & & $1.5^{* *}(0.09)$ & \\
\hline \multirow[t]{2}{*}{ Tasks = easy } & $0.19(0.10)$ & & $0.30 * *(0.09)$ & \\
\hline & \multicolumn{4}{|c|}{ Model 2} \\
\hline Intercept & $-0.65 * *(0.24)$ & & $0.84 * *(0.23)$ & \\
\hline Brand satisfaction & $0.14(0.07)$ & & $-0.13(0.07)$ & \\
\hline Self-confidence & $0.20 *(0.08)$ & & $-0.05(0.07)$ & \\
\hline Tasks & $0.14 * *(0.03)$ & 0.62 & $-0.14 * *(0.03)$ & -0.63 \\
\hline
\end{tabular}

Note: Model 1: $N=40$. Cases included $=200$. Model 2: $N=40$. Cases included $=100 . * * p<.01, * p<.05$. The reference for the task's effect is contemplative. 
Table 6. Spearman correlation coefficients between self-confidence at the start of the experiment and the items of emotional user experience factors. Means and Friedman test statistics for the difference in the distributions between contemplative, easy, and impossible tasks are also displayed.

\begin{tabular}{|c|c|c|c|c|c|c|c|}
\hline \multirow{2}{*}{ Item } & \multicolumn{2}{|c|}{ Contemplative } & \multicolumn{2}{|c|}{ Functional Easy } & \multicolumn{2}{|c|}{ Functional Hard } & \multirow{2}{*}{$\chi^{2}(2)$} \\
\hline & $\rho$ & $\mathbf{M}$ & $\rho$ & $\mathbf{M}$ & $\rho$ & $\mathbf{M}$ & \\
\hline Success & .26 & 3.7 & .30 & 3.8 & .12 & 2.0 & $62.5^{*}$ \\
\hline determination & .41 & 3.4 & .40 & 3.7 & .11 & 2.7 & $42.8^{*}$ \\
\hline Efficacy & .43 & 3.3 & .04 & 3.5 & .00 & 2.1 & $48.6^{*}$ \\
\hline Vigilance & .46 & 3.5 & .45 & 3.6 & .15 & 3.1 & $19.7 *$ \\
\hline frustration & .24 & 1.2 & .10 & 1.5 & .07 & 2.4 & $49.9 *$ \\
\hline anxiousness & -.25 & 1.6 & -.15 & 1.5 & -.05 & 2.2 & $39.9 *$ \\
\hline confusion & -.07 & 1.5 & .05 & 1.9 & .07 & 3.1 & $62.7^{*}$ \\
\hline annoyance & -.10 & 1.1 & -.05 & 1.4 & .13 & 2.5 & $59.1 *$ \\
\hline
\end{tabular}

Note: $N=40$ (20 each group). $\rho=$ Spearman correlation coefficient. $\chi^{2}=$ Friedman test statistic with $d f=2 . * p<.0125$.

periments. The difference between the items is visible, especially between impossible tasks and contemplative tasks but also between easy and contemplative tasks. Further, Spearman correlations suggest, as previously observed, that baseline Self-confidence can better explain emotional responses during contemplative tasks than during functional tasks. This is especially evident for the items of Competence.

\section{Discussion}

The third experiment gave further support for the conclusions drawn from the first two experiments: the stance of the user affects his or her emotional experience. Stance not only has a direct effect on emotional user experience (H2) but also moderates the other determinants of emotional user experience, such as the stimulus itself (H1), task efficiency (H4), or self-confidence (post-hoc analysis). However, the emotional responses of the participants were not reflective only of stance in all three experiments, a strong correlation between task efficiency and emotional user experience factors was found (H3). Because task efficiency clearly affects emotional user experience (standardized coefficients larger than .60 were observed), one must ask the following: what would the emotional responses to contemplative tasks reflect? More detailed analyses in the three experiments suggest an answer to this question in contemplative tasks, emotional responses are, in fact, reflective of the self-confidence of the participant. The summary of the hypotheses and the results from all three experiments reported here are presented in Table 7.

The post-hoc analyses at the end of each experiment resulted in connecting the baseline self-confidence of the participant, measured as self-confidence before the experiment, and emotional user-experience factors. The main result of the comparisons between stances was to show that the intensity of the stance tends to decrease the correlation between Self-confidence, as reported at the start of the experiment, and emotional user experience, as reported after conducting tasks. This is important result because it suggests problems in terms of the internal validity of studies using the contemplative stance to study emotional user experience.

\section{GENERAL DISCUSSION}

As a whole, the results of the three experiments suggest that in a systematic manner, user experience depends on the properties of ongoing action and the respective stances. The activation 


\section{Table 7. Summary of the results of the three experiments}

\begin{tabular}{|c|c|c|c|}
\hline \multirow{2}{*}{ Hypothesis } & \multicolumn{3}{|c|}{ Experiment } \\
\hline & 1 & 2 & 3 \\
\hline $\begin{array}{l}\text { H1. The stance of the participant affects how different stimuli elicit emotional user } \\
\text { experience. }\end{array}$ & $\mathrm{s}$ & $\mathrm{s}$ & $\mathrm{s}$ \\
\hline H2. The stance of the participant has an impact on emotional user experience. & ns & $\mathrm{s}$ & $\mathrm{s}$ \\
\hline H3. Task efficiency has an impact on emotional user experience. & $\mathrm{s}$ & $\mathrm{s}$ & $\mathrm{s}$ \\
\hline $\begin{array}{l}\text { H4. The stance of the participant affects the impact of task efficiency on emotional user } \\
\text { experience }\end{array}$ & - & $\mathrm{s}$ & - \\
\hline
\end{tabular}

Note: $\mathrm{ns}=$ not supported, $\mathrm{s}=$ supported. $\mathrm{H} 4$ was considered only in the second experiment.

of two opposite emotional clusters, competence and frustration, was observed in the participants. This competence-frustration model has been found earlier and is central to the analysis of user experience in human-technology interaction (Saariluoma \& Jokinen, 2014). Content-wise, competence is associated with such emotions as success, determinacy, efficacy, and vigilance, while frustration is associated with anxiousness, confusion, and annoyance. Thus, the successful use of technical artefacts seems to be linked with feeling competent, while feeling frustrated is characterized by failures and difficulties. These results are linked with both the tasks and the stances.

The second and the third experiments illustrated that the difficulty of a task is associated with the amount of frustration produced. Because contemplative tasks are often less demanding than functional ones, it is understandable that frustration is more common emotional content in functional tasks than in contemplative tasks. Indeed, frustration is generally seen as an aggression-related emotion caused by obstacles (Berkovitz, 1989; Miller, 1941; Power \& Dalgleish, 1997). The general nature of frustration can thus make our results understandable and explain why frustration is a relevant emotional state in functional tasks. The emotional theme of frustration is consistent with the mental contents of users when they fail in using a technical device. Failures in tasks, particularly in reaching task goals, provoke frustration.
In contrast, successful performance leads to feelings of competence. These feelings are intimately related to such motive constructions as satisfaction, happiness, self-efficacy, selfconfidence, self-esteem, and trust (Bandura, 1982; Barbeite \& Weis, 2004). These concepts are important in analysing and understanding how people overcome their fear of technologies and using them. Also, the feeling of control belongs to this family of emotional and motivational phenomena, although the results reported here did not address this issue. The general results implicate that the emotional experience of the user is dependent on the stance, which the user adapts while interacting with technology. Thus, just looking at technical objects, such as web pages or a cars in a car show, calls different emotions than actually using these technical artefacts. It is therefore important, that user experience is always considered from the perspective of what people are really doing with the artefact or as one could also say the nature of the interaction. In the very least, the assumptions concerning the stances of the users, built within the experimental designs, need to be always explicated.

Explaining and analysing behavioural phenomena relevant to interacting with technical artefacts in user psychology is consistencybased, which means that the results in user psychological research should be consistent with generally known psychological facts and theories concerning the relevant phenomena so that they can be used to explain interaction 
phenomena (Saariluoma, 2005; Saariluoma \& Oulasvirta, 2010). The above discussion illustrates that the results are understandable in the light of psychological research.

From a user experience point of view, one can think about relationship between user experience and cognition and emotion in terms of mental contents. Human performance is always intentional and intention defines the prevailing stance towards a technical artefact (Brentano, 1874/1973; Dennett, 1989; Husserl, 1901-2, 1936; Searle, 1983). In the traditional psychology of perception, the meaning of stance to how people perceive objects has long ago empirically demonstrated in the phenomenon of accordance (Gibson, 1979), and similarly, attentional schema theories state that people may attend very differently to same environments (Neisser, 1976). It has been also shown that people can perceive and attend similarly an object such as a chessboard, but mentally represent them very differently so that bad ideas blocked good ones (Bilalic \& McLeod 2014; Saariluoma, 1995, 2001). In this family of selective encoding phenomena, the notion of stance refers to what people are doing. People encode information depending on what is relevant to their performance. Thus, failure and success refer to whether the goal of a given task is reached. Reaching the goal increases the feeling of competence, and failure increases the feeling of frustration. The different stances activate mental representations with different cognitive and emotional mental contents as well as respective user experiences, though the technical artefacts and environments are same. Different stances lead to different appraisal processes and respective user experiences. Appraisal combines these elements into cognitive and emotional contents (Lazarus, 2001; Scherer, 2009).

On a general level, user experience, as a psychological phenomenon, must be investigated by asking what people are doing with technical artefacts and what their mental contents are. It is essential to consider user experiences given the types of actions and situations people are involved in when they experience interac- tion. From our point of view, it is problematic to think that there are general, situation-free attributes of user experience. Emotions vary depending on what people are doing and how they mentally represent their actions. This is why all measurements should be related to the actions in question. The analysis of the relevant emotional and cognitive mental contents is essential, because it allows researchers to differentiate between different stances, tasks, and behaviours. Theoretically, it is not sufficient to assume that people have schemas, mental models, or other mental representations, because it is necessary to also know what the mental contents are in different situations. This leads to understanding how people act and experience.

Finally, one of the main goals of our investigation is to illustrate that user psychological discourse enables us to elaborate the standard discussion on user experience. Psychological concepts, methods, and theoretical ideas enable researchers to find new perspectives to old phenomena within user experience research. This does not mean that user experience research, or an earlier experience-focused paradigm, Kansei-engineering, would not be psychologically indifferent. They both are built on psychological methods such as Osgood's semantic differentials or modern emotional questionnaire practices (Nagamachi, 2011; Hassenzahl, 2010; Hassenzahl, Burmester, \& Koller, 2003). However, it is possible to use also the full scale of core theoretical concepts of modern psychology, such as mental representation, in studying user experience phenomena. In usability research and ergonomics this has been common (Anderson, Farell, \& Sauers, 1984; Hollnagel, 2006) Nevertheless, content-based psychological thinking, which sees that the information contents of mental representations or mental contents as the core concept in analysing and explaining human behaviours, provides further theoretical power to analysis of cognitive and emotional aspects of user experiences (Saariluoma \& Jokinen, 2014). This also justifies adopting the notion of user psychology as an equally logical concept in psychology as economic psychology or child psychology (Moran, 1981; Saariluoma, 
2005). Most importantly, understanding humantechnology interaction in a scientific valid and coherent manner allows for justifying design solutions (Saariluoma \& Nevala, 2006). When designing for better user experience, and finally, when designing for better quality of technological life, it is therefore necessary for scientists of human-technology interaction to offer this kind of understanding.

\section{CONCLUSION AND OUTLOOK}

It is important to remember that there exists not just a single psychology, but many different practical fields, such as child psychology, personality psychology, and traffic psychology. Similarly, problem of human-technology interaction can open its own subfield and kind of psychology. Our work is just one minor example about a huge system of knowledge, which can be used to improve human relation to human technology. Further, our empirical findings illustrate that human action and the cognitive and emotional contents of mental representations make differences in ways we experience interaction with technical tools. Frustration and competence are just examples of feelings that can be elicited in users when they interact with technology. Intuitively, one could argue that there are numerous other important action contexts, which elicit emotional representations. Thus, the idea of investigating other types of interaction situations and associated emotions opens new challenges for a user psychologically oriented interaction research in future. With these caveats, we can summarise the main points and thus clarify the scientific message for future investigations of emotional user experience:

1. Our main framework can be called user psychology as it approaches and explains the phenomena of human technology interaction using concepts, methods, facts and theories of modern psychology (Moran, 1981; Saariluoma, 2004);
2. User experience is a well-documented area of interaction design (Hassenzahl \& Tractinsky, 2006; Kuniavsky, 2003; Law, Roto, Hassenzahl, Vermeeren, \& Kort, 2009; Nagamachi, 2011; Norman, Miller, \& Henderson, 1995; Wright \& McCarthy, 2005), and hence it is reasonable to apply user psychological thinking to refine the analysis this phenomenon;

3. Emotional information processes form the most natural basis of analysing user experience. However, emotions are intimately linked with cognitions and hence also with actions. Thus, psychological process of appraisal becomes central when analysing user experience;

4. In modern psychology, mental representation is a central concept. Nevertheless, so far, relatively little attention has been paid to its information contents or mental contents as the explanatory concept (Allport, 1980; Fodor, 1990; Newell \& Simon, 1972). Mental content provides researcher with a natural ground concept in analysis experience as one experience differs from another with respect to its contents;

5. Different types of actions can be analysed, understood, explained by investigating the differences in mental contents in the minds of people. The main benefit of this approach is that it integrates existent psychological knowledge with the analysis of interaction, and enables the consideration of the underlying mental processes behind conscious experiences on which user experience is based using the whole intellectual capacity of modern psychology;

6. The goal of human-technology interaction research and subsequent informed design of technologies is better interaction in terms of human life and its quality (Leikas 2009, Saariluoma \& Leikas, 2010). Emotion is one central theme in understanding life and designing for it. 


\section{ACKNOWLEDGMENT}

The authors thank Piia Perälä and Johanna Silvennoinen for helping with carrying out the experiments reported here. The research has been supported by a Fimecc/Tekes programme UXUS (User Experience and Usability in Complex Systems).

\section{REFERENCES}

Allport, D. A. (1977). On knowing the meaning of words we are unable to report: The effects of visual masking. In S. Dornic (Ed.), Attention and performance, VI(pp. 505-533). New York:Academic Press.

Allport, D. A. (1980). Attention and performance. In G. Claxton (Ed.), Cognitive psychology: New directions (pp. 112-153). London: Routledge \& Kegan Paul.

Anderson, J. R., Farrell, R., \& Sauers, R. (1984). Learning to program lisp. Cognitive Science, 8(2), 87-129. doi:10.1207/s15516709cog0802_1

Arnold, M. D. (1960). Emotion and personality. New York: Columbia University Press.

Bandura, A. (1982). Self-efficacy mechanism in human agency. The American Psychologist, 37(2), 122-147. doi:10.1037/0003-066X.37.2.122

Barbeite, F. G., \& Weiss, E. M. (2004). Computer self-efficacy and anxiety scales for an internet sample: Testing measurement equivalence of existing measures and development of new scales. Computers in Human Behavior, 20(1), 1-15. doi:10.1016/ S0747-5632(03)00049-9

Bargas-Avila, J. A., \& Hornbaek, K. (2011). Old wine in new bottles or novel challenges: A critical analysis of empirical studies of user experience. Proceedings of the CHI 2011 Conference on Human Factors in Computing Systems. New York: ACM. doi:10.1145/1978942.1979336

Barrett, L. F. (2006). Are emotions natural kinds? Perspectives on Psychological Science, 1(1), 28-58. doi:10.1111/j.1745-6916.2006.00003.x PMID:19079552

Beck, A. T. (1976). Cognitive therapy and the emotional disorders. New York: Basic Books.
Berkowitz, L. (1989). Frustration-aggression hypothesis: Examination and reformulation. Psychological Bulletin, 106(1), 59-73. doi:10.1037/00332909.106.1.59 PMID:2667009

Bilalic, M., \& Mcleod, P. (2014). Why good thoughts block better ones. Scientific American, 310(3), 58-63. doi:10.1038/scientificamerican0314-74 PMID:24660332

Bower, G. (1981). Mood and Memory. The American Psychologist, 36(2), 121-148. doi:10.1037/0003066X.36.2.129 PMID:7224324

Brentano, F. (1973). Psychology from an empirical standpoint. London: Routledge \& Kegan Paul. (Original work published 1874)

Campbell, D. T., \& Fiske, D. W. (1959). Convergent and discriminant validation by the multitraitmultimethod matrix. Psychological Bulletin, 56(2), 81-105. doi:10.1037/h0046016 PMID:13634291

Carroll, J. M., \& Thomas, J. C. (1988). Fun. ACM SIGCHI Bulletin, 19(3), 21-24. doi:10.1145/49108.1045604

Dennett, D. (1989). Intentional stance. Cambridge, Mass: MIT-press.

Dolan, R. J. (2002). Emotion, cognition, and behavior. Science, 298(5596), 1191-1194. doi:10.1126/ science.1076358 PMID:12424363

Ekman, P. (1993). Facial expression and emotion. The American Psychologist, 48(4), 384-392. doi:10.1037/0003-066X.48.4.384 PMID:8512154

Ericsson, K., \& Simon, H. (1984). Protocol analysis. Cambridge, Mass.: MIT press.

Fodor, J.A. (1990). A theory of contents. Cambridge, Mass.: MIT press.

Frijda, N. H. (1986). The emotions. Cambridge: Cambridge University Press.

Gibson, J. J. (1979). The ecological approach to visual perception. Boston: Houghton Mifflin.

Hassenzahl, M. (2008). User experience (UX): Towards an experiential perspective on product quality. Proceedings of the International Conference of the Association Francophone d'Interaction Homme-Machine. New York: ACM. doi:10.1145/1512714.1512717

Hassenzahl, M. (2010). Experience design: Technology for all the right reasons. San Raphael, CA: Morgan \& Claypool. 
Hassenzahl, M., Burmester, M., \& Koller, F. (2003). AttrakDiff: Ein Fragebogen zur Messung wahrgenommener hedonischer und pragmatis- cher Qualität [AttrakDiff:Aquestionnaire for the measurement of perceived hedonic and pragmatic quality]. (pp. 187-196). Mensch \& Computer.

Hassenzahl, M., \& Tractinsky, N. (2006). User experience - a research agenda. Behaviour \& Information Technology, 25(2), 91-97. doi:10.1080/01449290500330331

Hollnagel, E. (2006). Task analysis: Why, what and how. In G. Salvendy (Ed.), Handbook of human factors and ergonomics (pp. 373-383). Hoboken, NJ: John Wiley. doi:10.1002/0470048204.ch14

Hox, J. J. (2010). Multilevel analysis (2nd ed.). Hove: Routledge.

Husserl, E. (1913). (1901-2). Logische Unterschungen I-II. Halle: Niemeyer.

Husserl, E. (1936). The crises of European science and transcendental phenomenology. Evanston: Northwestern University Press.

Ivonin, L., Chang, H. M., Chen, W., \& Rauterberg, M. (2013). Unconscious emotions: Quantifying and logging something we are not aware of. Personal and Ubiquitous Computing, 17(4), 663-673.doi:10.1007/ s00779-012-0514-5

Izard, C. E. (2009). Emotion theory and research: Highlights, unanswered questions, and emerging issues. Annual Review of Psychology, 60(1), 1-25. doi:10.1146/annurev.psych.60.110707.163539 PMID:18729725

Johnson-Laird, P. (1983). Mental models: Towards a cognitive science of language, inference, and consciousness. Cambridge, Mass.: Harvard University Press.

Kant, I. (1781). Kritikder Reinen Vernunft. Stuttgart: Philip Reclam.

Kruskal, J. B., \& Wish, M. (1978). Multidimensional scaling. Beverly Hills, California: SAGE Publications.

Kuniavsky, M. (2003). Observing the user experience. San Francisco: Morgan Kaufmann.

Law, E. L. C., Roto, V., Hassenzahl, M., Vermeeren, A. P., \& Kort, J. (2009). Understanding, scoping and defining user experience: A survey approach. Proceedings of the CHI 09 Conference on Human Factors in Computing Systems. New York: ACM. doi:10.1145/1518701.1518813
Lazarus, R. S. (1991). Cognition and motivation in emotion. The American Psychologist, 46(4), 352-367. doi:10.1037/0003-066X.46.4.352 PMID:2048794

Lazarus, R. S. (2001). Relational meaning and discrete emotions. In K. L. Scherer, A. Schorr, \& T. Johsntone (Eds.), Appraisal processes in emotion (pp. 37-67).

Lazarus, R. S., \& Lazarus, B. N. (1994). Passion and reason: Making sense of our emotions. New York: Oxford University Press.

Leikas, J. (2009). Life-based design - a holistic approach to designing human-technology interaction. Helsinki: Edita Prima Oy.

Maio, G. R. (2010). Mental representations of social values. Advances in Experimental Social Psychology, 42, 1-43. doi:10.1016/S0065-2601(10)42001-8

Markman, A. B. (1999). Knowledge representation. Hillsdale, NJ: Erlbaum.

McCarthy, J., Wright, P., \& Meekison, L. (2005). A practitioner-centered assessment of a user-experience framework. [IJTHI]. International Journal of Technology and Human Interaction, 1(2), 1-23. doi:10.4018/jthi.2005040101

Miller, N. E. (1941). The frustration-aggression hypothesis. Psychological Review, 48(4), 337-342. doi: $10.1037 / \mathrm{h} 0055861$

Moors, A., Ellsworth, P. C., Scherer, K. R., \& Frijda, N. H. (2013). Appraisal theories of emotion: State of the art and future development. Emotion Review, 5(2), 119-124. doi:10.1177/1754073912468165

Moran, T. P. (1981). Guest editor's introduction: An applied psychology of the user. [CSUR]. ACM Computing Surveys, 13(1), 1-11. doi: $10.1145 / 356835.356836$

Nagamachi, M.(2011). Kansei/affective engineering and the history of kansei/affective engineering in the world. In M. Nagamachi (Ed.), Kansei/affective engineering, 13 (pp. 1-12). Boca Raton: CRC-press.

Neisser, U. (1976). Cognition and reality. San Francisco: Freeman.

Newell, A., \& Simon, H. A. (1972). Human problem solving. Englewood Cliffs, N.J.: Prentice-Hall.

Norman, D. (2004). Emotional design. Why we love and hate everyday things. New York: Basic Books. 
Norman, D., Miller, J., \& Henderson, A. (1995). What you see, some of what's future and how we go about doing it: Hi at Apple computer. Proceedings of the CHI 1995 Conference on Human Factors in Computing Systems. New York: ACM.

Nunnally, J. C., \& Bernstein, I. H. (1994). Psychometric theory (3rd ed.). New York: McGraw-Hill, Inc.

Oatley, K. (1992). Best laid schemas. Cambridge: Cambridge University Press.

Öhman, A. (2008). Fear and anxiety. In M. Lewis, Havilland-Jones, \& F. Barrett (Eds.), Handbook of emotions (pp. 709-729).

Ortony, A., Clore, G., \& Collins, A. (1988). The cognitive structure of emotions. New York: Cambridge University Press. doi:10.1017/CBO9780511571299

Power, M. J., \& Dalgleish, T. (1997). Cognition and emotion: From order to disorder. Hove: Psychology Press.

Russell, J. A. (1980). A circumplex model of affect. Journal of Personality and Social Psychology, 39(6), 1161-1178. doi:10.1037/h0077714

Russell, J. A. (2003). Core affect and the psychological construction of emotion. Psychological Review, 110(1), 145-172. doi:10.1037/0033-295X.110.1.145 PMID:12529060

Saariluoma, P. (1995). Chess players' thinking. London: Routledge.

Saariluoma, P. (1997). Foundational analysis. London: Routledge.

Saariluoma, P. (2001). Chess and content-oriented psychology of thinking. Psychologica, 22, 143-164.

Saariluoma, P. (2003). Apperception, content based psychology and design. In U. Lindemann (Ed.), Human behaviour in design (pp. 72-78). Berlin: Springer. doi:10.1007/978-3-662-07811-2_8

Saariluoma, P. (2005). Explanatory frameworks in interaction design. In A. Pirhonen, H. Isomäki, H. C. Roast, \& P. Saariluoma (Eds.), Future interaction design (pp. 67-83). London: Springer. doi:10.1007/184628-089-3_5

Saariluoma, P., \& Jokinen, J. P. P. (2014). Emotional dimensions of user psychology-a user psychological analysis. International Journal of Human-technology Interaction, 30(4), 303-320. doi:10.1080/1044731 8.2013.858460

Saariluoma, P., \& Leikas, J. (2010). Life-based design - an approach to design for life. Global Journal of Management and Business Research, 10(5), 17-23.
Saariluoma, P. \& Nevala, K. (2006). The focus of content-based design analysis - a reply Eder. Proceedings of Applied Engineering Design Science 2006.

Saariluoma, P., \& Oulasvirta, A. (2010). User psychology: Re-assessing the boundaries of a discipline. Psychology (Savannah, Ga.), 1(5), 317-328.

Schachter, S., \& Singer, J.E.(1962). Cognitive, social and psychological determinants of emotional state. Psychological Review, 69(5),379-399. doi:10.1037/ h0046234 PMID:14497895

Scherer, K. R. (2005). What are emotions? And how can they be measured? Social Sciences Information. Information Sur les Sciences Sociales, 44(4), 695-729. doi:10.1177/0539018405058216

Scherer, K. R. (2009). The dynamic architecture of emotion: Evidence for the component process model. Cognition and Emotion, 23(7), 1307-1351. doi:10.1080/02699930902928969

Schoepenhauer, A. (1969). The world as will and representation (pp. 1818-1919). New York: Dover Publications.

Schorr, A. (2001). Subjective measurement in appraisal research. In K. R. Scherer, A. Schorr, \& T. Johnstone (Eds.), Appraisal Processes in Emotion (pp. 331-349). New York: Oxford University Press.

Searle, J. (1983). Intentionality: An essay in the philosophy of mind. Cambridge: Cambridge University Press. doi:10.1017/CBO9781139173452

Smith, C., \& Ellsworth, P. C. (1985). Patterns of cognitive appraisal in emotion. Journal of Personality and Social Psychology, 48(4), 813-838. doi:10.1037/0022-3514.48.4.813 PMID:3886875

Teasdale, J. D., \& Barnard, P. J. (1993). Affect, cognition and change. Hove: Erlbaum.

Vermeeren, A. P., Law, E. L. C., Roto, V., Obrist, M., Hoonhout, J., \& Väänänen-Vainio-Mattila, K. (2010). User experience evaluation methods: Current state and development needs. Proceedings of the 6th Nordic conference on human-computer interaction: Extending boundaries. New York:ACM. doi:10.1145/1868914.1868973

Wittgenstein, L.(1958). Philosophical investigations. Oxford: Basil Blackwell.

Wright, P., \& McCarthy, J. (2005). The value of novel in design for experience. In A. Pirhonen, $\mathrm{H}$. Isomäki C. Roast, \& P. Saariluoma (Eds.), Future interaction design (pp. 9-30). London: Springer. doi:10.1007/1-84628-089-3_2 
Pertti Saariluoma has presented his thesis on expertise in the University of Turku 1984. He has studied, worked and visited in Oxford, Carnegie-Mellon, Cambridge, Aberdeen, IIASA, University of Granada. Presently, he works as the Professor of Cognitive Science in the University of Jyväskylä, Finland. His interests include expertise, thinking, foundations of science, design of technologies, and innovation processes.

Jussi P.P. Jokinen is a doctoral student of cognitive science at Department of Computer Science and Information Systems, University of Jyväskylä. His research involves experience and emotion in human-technology interaction. 


\section{APPENDIX A}

\section{Questionnaire Items}

Table 8. Participant pre-task questionnaire

\begin{tabular}{|l|}
\hline \multicolumn{1}{|c|}{ Brand Satisfaction } \\
\hline The brand offers me solutions. \\
\hline The brand offers me professionalism. \\
\hline The brand supports my intentions. \\
\hline I could use the products of this brand more than once. \\
\hline \\
\hline The brand has a good reputation. \\
\hline The brand is safe. \\
\hline The actions of the brand are trustworthy. \\
\hline Honesty describes the brand. \\
\hline \\
\hline I feel certain. \\
\hline I feel determined. \\
\hline I feel ready. \\
\hline I feel vigilant. \\
\hline
\end{tabular}

Note: Items for brand experience were rated on a 5-point Likert scale from 'strongly disagree' to 'strongly agree'. Items for Self-confidence were rated on a 5-point Likert scale: 'not at all', 'a little', 'somewhat', 'much', and 'very much'.

\section{Table 9. Participant emotional questionnaire}

\begin{tabular}{|l|}
\hline \multicolumn{1}{|c|}{ Competence } \\
\hline I felt successful. \\
\hline I felt determined. \\
\hline I felt efficient. \\
\hline I felt vigilant. \\
\hline \\
\hline I felt frustrated. \\
\hline I felt anxious. \\
\hline I felt confused. \\
\hline I felt annoyed. \\
\hline
\end{tabular}

Note: Items rated on a 5-point likert scale: 'not at all', 'a little', 'somewhat', 'much', and 'very much'. 


\section{APPENDIX B}

\section{Factor Loadings and Multilevel Model Effects}

Table 10. Factor loadings for competence and frustration in the two groups, experiment 1

\begin{tabular}{|c|c|c|}
\hline \multirow{2}{*}{ Item } & \multicolumn{2}{|c|}{ Factor Loading } \\
\hline & Cont. & Funct. \\
\hline Compete & & \\
\hline success & .89 & .89 \\
\hline determination & .85 & .92 \\
\hline efficacy & .85 & .93 \\
\hline vigilance & .59 & .73 \\
\hline Frustrati & & \\
\hline frustration & .73 & .75 \\
\hline anxiousness & .81 & .77 \\
\hline confusion & .64 & .87 \\
\hline annoyance & .58 & .90 \\
\hline
\end{tabular}

Note: $N=40$ (20 for each group) Funct. = functional tasks. Cont. = contemplative tasks.

Table 11. Factor loadings for competence and frustration in the two groups, experiment 2

\begin{tabular}{|c|c|c|}
\hline \multirow{2}{*}{ Item } & \multicolumn{2}{|c|}{ Factor Loading } \\
\hline & Easy & Hard \\
\hline Compete & & \\
\hline success & .80 & .89 \\
\hline determination & .74 & .74 \\
\hline efficacy & .93 & .88 \\
\hline vigilance & .53 & .61 \\
\hline Frustrati & & \\
\hline frustration & .82 & .83 \\
\hline anxiousness & .43 & .70 \\
\hline confusion & .57 & .75 \\
\hline annoyance & .67 & .92 \\
\hline
\end{tabular}

Note: $N=40$ (20 for each group). Easy = easy tasks. Hard = difficult tasks. 
Table 12. Factor loadings for competence and frustration in the three groups, experiment 3

\begin{tabular}{|l|l|l|l|}
\hline \multirow{2}{*}{\multicolumn{2}{c|}{ Item }} & \multicolumn{3}{c|}{ Factor Loading } \\
\cline { 2 - 4 } & \multicolumn{2}{c|}{ Cont. } & \multicolumn{2}{c|}{ Easy } & \multicolumn{2}{c|}{ Imp. } \\
\hline \multicolumn{1}{|c|}{ Competence } & & & .79 \\
\hline success & .71 & .84 & .81 \\
\hline determination & .91 & .87 & .85 \\
\hline efficacy & .83 & .79 & .58 \\
\hline vigilance & .61 & .72 & \\
\hline \multicolumn{1}{|c|}{ Frustration } & & & .75 \\
\hline frustration & .66 & .81 & .80 \\
\hline anxiousness & .70 & .72 & .57 \\
\hline confusion & .66 & .74 & .79 \\
\hline annoyance & .71 & .80 & \\
\hline
\end{tabular}

Note: $N=40$. Cont. $=$ contemplative tasks. Easy $=$ easy tasks. Imp. $=$ Impossible tasks.

Table 13. The effect sizes for multilevel models predicting competence and frustration, experiment 1

\begin{tabular}{|c|c|c|c|c|c|c|}
\hline & \multicolumn{3}{|c|}{ Competence } & \multicolumn{3}{|c|}{ Frustration } \\
\hline & $\mathbf{F}$ & df1 & df2 & $\mathbf{F}$ & df1 & df2 \\
\hline & \multicolumn{6}{|c|}{ Model 1} \\
\hline Model & $8.8 * *$ & 3 & 183 & $7.3 * *$ & 3 & 162 \\
\hline Brand satisfaction & 0.6 & 1 & 188 & 1.6 & 1 & 186 \\
\hline Certainty & $25.3 * *$ & 1 & 180 & $20.8^{* *}$ & 1 & 148 \\
\hline \multirow[t]{2}{*}{ Group } & 0.0 & 1 & 187 & 0.2 & 1 & 147 \\
\hline & \multicolumn{6}{|c|}{ Model 2} \\
\hline Model & $23.3 * *$ & 3 & 67 & $13.3^{* *}$ & 3 & 56 \\
\hline Brand satisfaction & 1.8 & 1 & 77 & 1.3 & 1 & 47 \\
\hline Certainty & 3.1 & 1 & 81 & $4.5^{*}$ & 1 & 80 \\
\hline Time & $66.0 * *$ & 1 & 77 & $26.7 * *$ & 1 & 66 \\
\hline
\end{tabular}

Note: Model 1: $N=40$, Model 2: $n=19 .{ }^{* *} p<.01,{ }^{*} p<.05$. 
Table 14. The effect sizes for multilevel models predicting competence and frustration, experiment 2

\begin{tabular}{|l|l|l|l|l|l|l|}
\hline \multirow{2}{*}{} & \multicolumn{3}{|c|}{ Competence } & \multicolumn{1}{c|}{ Frustration } \\
\cline { 2 - 7 } & \multicolumn{1}{|c|}{ F } & \multicolumn{1}{c|}{ df1 } & \multicolumn{1}{c|}{ df2 } & \multicolumn{1}{c|}{ F } & \multicolumn{1}{c|}{ df1 } & df2 \\
\hline Model & $20.1^{* *}$ & 5 & 179 & $17.2^{* *}$ & 5 & 163 \\
\hline Brand satisfaction & $5.1^{*}$ & 1 & 190 & 1.0 & 1 & 161 \\
\hline Self-confidence & 0.6 & 1 & 187 & 0.1 & 1 & 176 \\
\hline Group & $4.0^{*}$ & 1 & 175 & $15.8^{* *}$ & 1 & 179 \\
\hline Tasks & $92.3^{* *}$ & 1 & 177 & $54.6^{* *}$ & 1 & 162 \\
\hline Group $\times$ tasks & $8.1^{* *}$ & 1 & 179 & $10.9^{* *}$ & 1 & 163 \\
\hline
\end{tabular}

Note: $N=40 . * * p<.01, * p<.05$.

Table 15. The effect sizes for multilevel models predicting competence and frustration, experiment 3

\begin{tabular}{|c|c|c|c|c|c|c|}
\hline & \multicolumn{3}{|c|}{ Competence } & \multicolumn{3}{|c|}{ Frustration } \\
\hline & $\mathbf{F}$ & df1 & df2 & $\mathbf{F}$ & df1 & df2 \\
\hline & \multicolumn{6}{|c|}{ Model 1} \\
\hline Model & $50.9 * *$ & 4 & 300 & $67.1 * *$ & 4 & 234 \\
\hline Brand satisfaction & $14.0 * *$ & 1 & 342 & $4.8^{*}$ & 1 & 225 \\
\hline Self-confidence & $44.3 * *$ & 1 & 359 & 1.2 & 1 & 244 \\
\hline \multirow[t]{2}{*}{ Task group } & $74.2 * *$ & 2 & 262 & $131.2^{* *}$ & 1 & 234 \\
\hline & \multicolumn{6}{|c|}{ Model 2} \\
\hline Model & $9.9^{* *}$ & 3 & 90 & $7.7 * *$ & 3 & 78 \\
\hline Brand satisfaction & 3.9 & 1 & 93 & 3.8 & 1 & 84 \\
\hline Self-confidence & $6.6^{*}$ & 1 & 80 & 0.4 & 1 & 66 \\
\hline Tasks & $22.6 * *$ & 1 & 90 & $23.1 * *$ & 1 & 89 \\
\hline
\end{tabular}

Note: Model 1: $N=40$. Included cases $=400$. Model 2: $N=40$. Included cases $=100 . * * p<.01, * p<.05$. 